\title{
COMPARISON OF DP PERFORMANCE PREDICTION TECHNIQUES FOR SCALED MODELS
}






\title{
Comparison of DP Performance Prediction Techniques for Scaled Models
}

\author{
by \\ (C) Stephen P. Very \\ B.A.Sc., University of British Columbia, 2008
}

A thesis submitted to the School of Graduate Studies in partial fulfillment of the requirements for the degree of Master of Engineering

Faculty of Engineering and Applied Science

Memorial University of Newfoundland

March 2012

St. John's

Newfoundland 


\section{Abstract}

Utilization of Dynamic Positioning (DP) systems for offshore exploration and production of hydrocarbons is increasing due to the need to exploit deeper water depths, where mooring becomes less feasible. In conducting analysis or predictions for DP System performance, there are three common techniques: experimental investigations at reduced scale, using a simplified mooring system without thrusters; similarly scaled experiments using active DP thrusters; or, time or frequency domain numerical simulations. This paper identifies differences in DP system performance estimates, provided by each of the three methods, by using each method to analyze the same system, in identical wind and wave environments. Experiments were completed using a 1:40 scale model of a typical 99,000t monohull drillship equipped with an active DP system consisting of six azimuthing thrusters. These experiments were repeated with the vessel unpowered on two mooring systems with different stiffnesses. Physical experimental results are then compared to time-domain numerical simulations completed using Oceanic Consulting Corporation's DP simulation program. A comparison of system performance predictions provided by each method is presented. 


\section{Acknowledgements}

I would like to take this opportunity to thank my supervisors, Dr. Bruce Colbourne and

Dr. Dan Walker for their support and guidance. The work described in this paper was carried out as part of a project which was supported by the Atlantic Innovation Fund administered by Atlantic Canada Opportunities Agency with additional financial support from Husky Energy Canada. The support from these two organizations is gratefully acknowledged.

I would also like to thank the following organizations: Oceanic Consulting Corporation for their support and the funding to complete these experiments, and The National Research Council-Institute of Ocean Technology for the use of their equipment, facilities and support personnel. In that respect, I thank Dr. James Millan, Mr. David Millan, Dr. David Molyneux, and Mr. Don Spencer.

Finally, and most importantly, I would like to thank my family; my mother Afton and father Pat, and my dear friend Penny for their love and support. 


\section{TABLE OF CONTENTS}

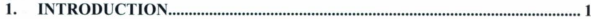

2. BACKGROUND AND RELATED WORK ……...................................................... 3

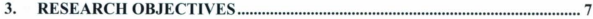

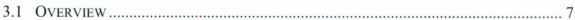

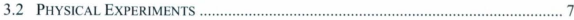

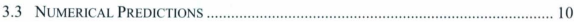

4. METHODOLOGY - PHYSICAL EXPERIMENTS ........................................ 12

4.1 FACILITIES - IOT OFFSHORE ENGINEERING BASIN ……..................................... 12

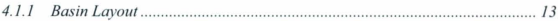

4.2 VeSSEL MODEL

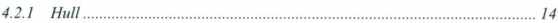

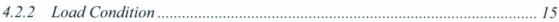

4.2.3 Propulsion Equipment ………........................................................ 16

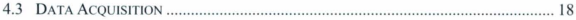

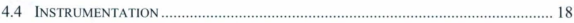

4.4.I Wind Speed Calibration …................................................................... 19

4.5 DP SYSTEM

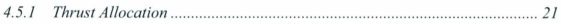

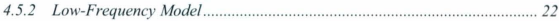

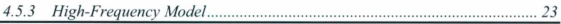


4.6 EXPERIMENTAL Program (TESTING MATRIX) ................................................ 24

4.6.1 Roll, Pitch and Mooring Decays......................................................... 25

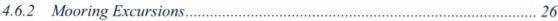

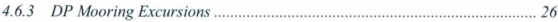

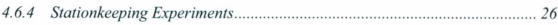

4.6.4.1 Experimental Matrix ....................................................................... 26

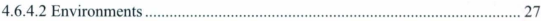

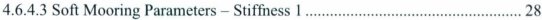

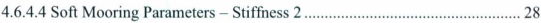

4.6.4.5 Dynamic Positioning Parameters ....................................................... 28

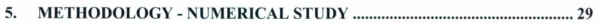

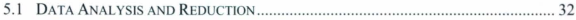

5.2 RESPONSE AMPLITUDE OPERATORS............................................................... 32

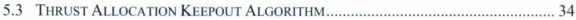

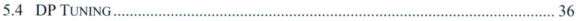

5.5 Physical Stationkeeping Evaluations.................................................... 39

5.6 NUMERICAL STATIONKEEPING EVALUATIONS ................................................... 42

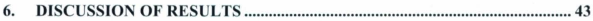

6.1 COMPARISON OF PHYSICAL StATIONKEEPING ForCES ..................................... 43

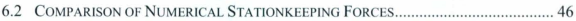

6.3 THE EFFECTS OF KEEPOUT ZONES ................................................................ 48 
6.4 THE EFFECTS OF ALTERED DP TUNING IN OFFSETS AND WAVES

6.5 MEASUREMENT UNCERTAINTY.....

7. CONCLUSIONS AND FURTHER WORK ....................................................... 53

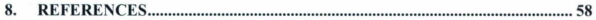




\section{LIST OF TABLES}

Table 1: IOT Offshore Engineering Basin (OEB) Particulars ....................................12

Table 2: Wave Maker Utilization ...........................................................................13

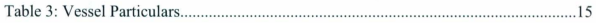

Table 4: Thruster Locations (model scale) ................................................................. 16

Table 5: Instrumentation List - Stationkeeping Experiments ......................................19

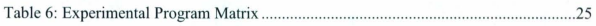

Table 7: Irregular Wave Experiment Matrix ….............................................................27

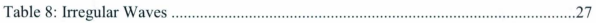

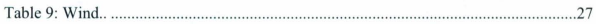

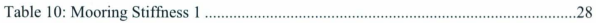

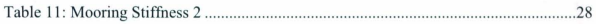

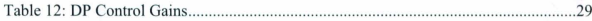

Table 13: Effect of Keepout Logic on Stationkeeping Force and Position Error ...............36

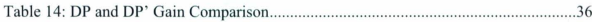

Table 15: Effect of DP Tuning on Stationkeeping Force and Position Error .....................39

Table 16: Full-Scale Mean Stationkeeping Forces (tonnes) ............................................ 41

Table 17: Mooring Force with respect to DP Force …................................................ 41

Table 18: FS Mean Stationkeeping Forces (tonnes) ...................................................42

Table 19: Mooring Force with respect to DP Force ….................................................43

Table 20: Model Scale Stationkeeping Force Components ...........................................46

Table 21: MS Numerical Stationkeeping Force Components ...................................47 
Table 22: MS Numerical Mooring Force Comparison

Table 23: Measurement Uncertainties

\section{LIST OF FIGURES}

Figure 1: Basin Layout, Head Wind Configuration ......................................................13

Figure 2: Basin Layout, Beam Wind Configuration .............................................. 14

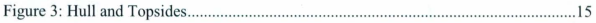

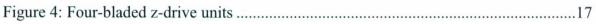

Figure 5: DP Control System Structure, Modified from Saelid (1983) .........................20

Figure 6: MOTSIM Operations Overview, compiled from Pawlowski (1991) and Peng (2006)

Figure 7: Effect of Keepout Algorithm on Bollard Thrust .35

Figure 8: Surge response of as-experimented DP tuning (left) and alternate tuning DP'

$$
\text { (right) }
$$

Figure 9: Sway response of as-experimented DP tuning (left) and alternate tuning DP'

$$
\text { (right) }
$$

Figure 10: Yaw response of as-experimented DP tuning (left) and alternate tuning DP'

$$
\text { (right) }
$$
.38

Figure 11: Image of the vessel under DP control in waves 40

Figure 12: Panelized Hull Render. 42

Figure 13: FS Beam Seas Head Wind Position and Force. .44 
Figure 14: FS Beam Seas Beam Wind Position and Force.

\section{LIST OF ABBREVIATIONS AND SYMBOLS}

\begin{tabular}{|c|c|}
\hline$\Delta$ & Displacement [tonnes] \\
\hline$\varepsilon$ & Relative damping ratio \\
\hline$\phi, \phi_{A}$ & Roll angle [deg] \\
\hline$\lambda$ & Scale factor \\
\hline$\pi$ & Constant [3.1415927] \\
\hline$\tau$ & Control demand vector \\
\hline$\theta$ & Pitch angle, or trim [deg] \\
\hline$\rho, \rho_{M}, \rho_{S}$ & Density of water for model or ship $\left[\mathrm{kg} / \mathrm{m}^{3}\right.$, tonnes $\left./ \mathrm{m}^{3}\right]$ \\
\hline$v_{M}, v_{S}$ & Kinematic viscosity of water for model or ship $\left[\mathrm{m}^{2} / \mathrm{s}\right]$ \\
\hline$\psi$ & Yaw angle [deg] \\
\hline$\omega_{W}$ & Wave frequency $[\mathrm{rad} / \mathrm{sec}]$ \\
\hline$\xi_{A}$ & Wave amplitude $[\mathrm{m}]$ \\
\hline$A P$ & Aft perpendicular \\
\hline$B$ & Beam $[\mathrm{m}]$ \\
\hline$D$ & Damping [N.s/m] \\
\hline$F$ & Force $[\mathrm{N}$, tonnes $]$ \\
\hline
\end{tabular}




\begin{tabular}{|c|c|}
\hline FP & Forward perpendicular \\
\hline$F S$ & Full scale \\
\hline$g$ & Gravitational acceleration $\left[9.808 \mathrm{~m} / \mathrm{s}^{2}\right]$ \\
\hline$G M_{T}$ & Transverse metacentric height $[\mathrm{m}]$ \\
\hline$h$ & Water depth [m] \\
\hline$h(s)$ & HF motion spectrum \\
\hline$H_{S}$ & Significant wave height $[\mathrm{m}]$ \\
\hline IOT & Institute for Ocean Technology \\
\hline ITTC & International Towing Tank Conference \\
\hline$K_{w}$ & DP tuning parameter; sea state dependent \\
\hline$k_{X X}$ & Mass radius of gyration in roll $[\mathrm{m}]$ \\
\hline$k_{Y Y}$ & Mass radius of gyration in pitch [m] \\
\hline$L_{M}, L_{S}$ & Length of model or ship [m] \\
\hline$L C B$ & Longitudinal center of buoyancy $[\mathrm{m}]$ \\
\hline$L C G$ & Longitudinal center of gravity $[\mathrm{m}]$ \\
\hline$M$ & Inertia $[\mathrm{kg}]$ \\
\hline$m$ & Mass [kg, tonnes] \\
\hline$M S$ & Model scale \\
\hline$n$ & Rotation rate [rps, RPM] \\
\hline$N_{\dot{r}}$ & Added moment of inertia in yaw \\
\hline$O C C$ & Oceanic Consulting Corporation \\
\hline
\end{tabular}




\begin{tabular}{|c|c|}
\hline$O E B$ & Offshore Engineering Basin \\
\hline$R A O$ & Response amplitude operator \\
\hline s & LaPlace frequency domain variable \\
\hline$S_{\omega}$ & Spectral energy $\left[\mathrm{m}^{2} /(\mathrm{rad} / \mathrm{s})\right]$ \\
\hline$S D$ & Standard Deviation \\
\hline$T$ & Draft $[\mathrm{m}]$ \\
\hline$T_{a}$ & Thruster allocation matrix \\
\hline$T_{t h}$ & Thruster demand vector \\
\hline$T C G$ & Transverse center of gravity $[\mathrm{m}]$ \\
\hline$u_{A}, u_{B}, u_{C}$ & Type A, B, and Combined uncertainties [\%] \\
\hline$V C G$ & Vertical center of gravity $[\mathrm{m}]$ \\
\hline$w_{a}$ & Gaussian white noise processes \\
\hline$w_{0}$ & DP tuning parameter; proportion of HF transmitted to feedback loop \\
\hline$X$ & Surge translation; $\mathrm{x}$-direction; positive sense is forward [m] \\
\hline$X_{\dot{u}}, Y_{\dot{v}}$ & Surge and sway hydrodynamic added mass $[\mathrm{kg}]$ \\
\hline$Y$ & $\begin{array}{l}\text { Sway translation; } y \text {-direction; positive sense is to starboard when looking } \\
\text { along the } x \text {-axis in the positive direction }[\mathrm{m}]\end{array}$ \\
\hline$Z$ & $\begin{array}{l}\text { Heave translation; } z \text {-direction; vertical direction; positive sense acts down } \\
{[\mathrm{m}]}\end{array}$ \\
\hline
\end{tabular}




\section{LIST OF APPENDICES}

APPENDIX A: ADDITIONAL PHYSICAL MODELLING INFORMATION..... A-1 APPENDIX B: RESPONSE AMPLITUDE OPERATORS ................... B-1 APPENDIX C: GRAPHICAL RESULTS OF DP ALGORITHM ADJUSTMENT C-1 APPENDIX D: GRAPHICAL PHYSICAL STATIONKEEPING RESULTS....... D-1 APPENDIX E: GRAPHICAL NUMERICAL STATIONKEEPING RESULTS... E-1 APPENDIX F: UNCERTAINTY ANALYSIS ............................. F-1 


\section{INTRODUCTION}

Dynamic Positioning (DP) systems are increasingly used on vessels and offshore platforms as a means of maintaining vessel or platform position during marine operations or production activities. These DP systems are a substantial capital investment and thus the system design process seeks to optimize a given installation. In order to optimize a design it is necessary to predict the environmental forces on a proposed vessel and predict the performance of a DP system under these environmental loads. These predictions are somewhat complicated by the fact that a DP system is a reactive system that responds to the applied environmental loads.

Physical experiments, using a scaled prototype of a Dynamically Positioned (DP) vessel, are often conducted to estimate full-scale positioning system performance in varying environments. Positioning system performance is most often quantified in terms of a Watch Circle, which is the radius of the maximum excursion of the vessel under DP control in a given environment. This is essentially a measure of stationkeeping ability. The primary environmental parameters of interest in assessing DP watch circle performance are wind, current and second order wave loads on the vessel. These forces can be measured using, a moored model, or a model with a full DP system, or calculated using numerical methods.

In the experiments conducted for this study, the prototype is held on station using either a simplified mooring system or an active DP system and examined in the required 


\section{Comparison of DP Performance Prediction Techniques for Scaled Models}

environments. A time-domain numerical simulation of the same vessel under DP control was also conducted, and the numerical results compared with the experimental predictions. The main driver in the choice between passive or active physical experimental methods is generally cost. Development costs for a fully functioning scaled prototype outfitted with active thrusters and a control system are considerably higher than those for an unpowered model. Linear and non-linear numerical simulations can also be used for stationkeeping force prediction, which can be less expensive than rigorous physical modeling programs. However, the majority of these simulations are based on potential flow theory and therefore require some physical calibration data to accurately model viscous effects. The objective of this study was to quantify some of the variances in measured stationkeeping forces evaluated using each of these methods and to assist designers in the choice of modeling techniques for DP watch circle evaluation.

This study compares and quantifies variances in the measurements of first and second order wave forces and motions for three common DP vessel evaluation techniques: 1) full-DP model testing, 2) soft-moored model testing, and 3) time-domain numerical simulation. The main goal of this study was to determine if there were significant differences in predictions between experimental methods by comparing the moored case to an unmoored full-DP case in wind, regular and irregular waves. A secondary goal was to identify areas of strength and weakness in terms of the predictions generated by the two experimental approaches and the numerical method. It was postulated that each of 
the three prediction methods would have inherent weaknesses but that a combined method might offer the best, and most cost effective DP prediction method.

The same apparatus was used for all experiments. The only changes between experimental programs were: the DP thrusters were inactive for the soft-moored experiments; and, the moorings were disconnected for the full-DP program. The softmoored and full-DP setups were exposed to an identical series of wind, current and wave environments. A comparison of predicted stationkeeping forces from each of the three approaches is presented. In addition, some experiments were conducted involving the modification of DP control parameters and there was an exercise in matching of RAOs between physical and numerical simulations. The results from these additional analyses are presented.

\section{BACKGROUND AND RELATED WORK}

As onshore and shallow water oil reserves are exhausted, the trend in exploration is towards previously inaccessible deposits, often found below the seafloor of deep oceans. Traditionally, floating offshore structures in moderate water depths are held on station using massive cable or chain mooring systems. In deep water, the necessitated increase in mooring line length increases line weight and makes the moorings difficult and costly to manufacture, transport and install. Mooring weight can also decrease the storage payload of a floating structure. An economical stationkeeping solution in deep water is often DP or DP assisted mooring. 
Comparison of DP Performance Prediction Techniques for Scaled Models

Marine Dynamic Positioning (DP) defines the process of holding a floating structure at a specified location, or on a specified trajectory, by the application of a summed correction force, generally applied using thrusters, to minimize course or station deviation. The correction force is calculated by taking as inputs, measured position error and estimated environmental forces acting on the structure. Thus, the acquisition of experimental or numerical predictions of DP performance in advance of the design process can assist in the optimization of such systems.

Much work has been done since the 1960's to refine the control algorithms through which position error and environmental forces are estimated and summed to provide a single, continuously updated, control force vector within a Dynamic Positioning System. In the infancy of DP control systems, controllers typically consisted of single-input single-output (SISO) Proportional-Integral-Differential (PID) controllers with notch filtering, In the 1970's a multi-input multi-output (MIMO) PID controller mated to an Extended Kalman Filter (EKF) was first introduced. The refinement of this approach has carried on to the present time for control in low to moderate sea states, with the addition of adaptive control strategies in later years, used to automatically update wave filtering frequencies for varying sea states. PID controllers used in conjunction with innovations such as acceleration feedback (AFB) and anti-spin thruster actuation have been implemented for stationkeeping in extreme sea states, where it is no longer beneficial to filter first order wave forces. (Sørensen, 2011) 
Comparison of DP Performance Prediction Techniques for Scaled Models

There are very few published experiments utilizing model-scale DP-systems. Aalbers (1996) presented model test findings using a 1:70 scale, DP assisted, turret moored FPSO with three azimuthing thrusters. Stationkeeping performance, as well as turning capabilities in various sea states and water depths for the DP assisted mooring system on the SPU380 FPSO were analyzed. There was also a focus on tuning of the DP assisted mooring system.

Wichers (1998) conducted DP model tests using a 1:65 scale monohull deep water drilling vessel with six azimuthing thrusters. DP heading capabilities, determined from the model tests, were compared to time domain computer simulations modeling the same vessel and controller. Both collinear wind-wave cases and waves with beam squalls with varying wind speed were investigated. Results of thruster-hull and thruster-thruster interaction were also presented.

Kim, H. (2002) compares heading windows of a 145KDWT shuttle tanker in combined environments, measured using three methods: a time domain simulation, static analysis based on mean environmental forces, and physical model experiments utilizing a 1:60 scale full-DP model. In all simulations, the azimuth thruster was fixed athwartships and no rudder action was utilized. A fixed-gain PD controller, with an EKF wave filter, wind feed-forward, and a fixed-angle thrust allocation was implemented. Ballast and full load conditions were considered. A large variation in results was displayed in the ballast condition, attributed to thrust degradation of thrusters close to the free surface in waves 
Comparison of DP Performance Prediction Techniques for Scaled Models

and current. Results at full load displayed $+/-5-10$ degree heading window variations between measurement methods.

Tannuri (2006) described the validation of a time-domain computational dynamic simulator for DP systems (Numerical Offshore Tank) using a 1:150 scale physical model of a DP tanker with 3 thrusters (a bow and stern thruster and one main propeller) in two loading conditions. The physical and numerical simulations utilized the same DP controller, which comprised of a PD controller, an EKF and an optimal thrust allocation algorithm. Numerical wave drift forces were calculated using WAMITTM, a linear potential flow analysis.

Tannuri (2009) (1\&2) compared measurements from a full-scale DP offloading operation to the same operation run using the time-domain computational dynamic simulator described in Tannuri (2006).

Research involving physical models completed to date generally features experiments using relatively small-scale simplified models for the purpose of comparison to numerical predictions of watch circle performance. Control action in these models is matched by comparing DP step responses. Such experiments assume the physical DP results to be an accurate baseline from which to compare the numerical models. None of the experiments to date compare performance of the physical DP model to that found using other physical modeling techniques such as soft moorings. 
The focus of this study is the variation in environmental loads measured using a range of common pre-installation performance modeling techniques spanning a range of economic options, from an unpowered physical model on a four-point horizontal mooring, to a time-domain numerical simulation, to a fully powered, DP controlled physical model. By quantifying the change in mean loads for a series of environmental headings, ranging from best to worst case stationkeeping scenarios, an understanding can be gained of what impact the choice of measurement method, and therefore investment in modeling, will have on the estimated DP capability plot.

\section{RESEARCH OBJECTIVES}

\subsection{Overview}

In this study, stationkeeping forces for a DP tanker were evaluated physically using two commercially available reduced scale modeling techniques. These results were compared to those obtained using a non-linear time domain numerical simulation. The objective of this comparison is to highlight potential result variances between each method and experimental uncertainties inherent in each method.

\subsection{Physical Experiments}

It is widely believed for reduced scale physical modeling that the more detailed a model, the more accurate the result. Following from this, a self-powered, untethered DP model is considered to be the best means available for modeling a full scale DP ship. However, powered DP models require relatively complex mechanical components and software 
systems to operate and are therefore expensive to design and construct. It is for this reason that instrumented soft moorings are often used in place of powered thrusters to hold a model on station and measure the environmental loads. Soft moorings generally are a four-point horizontal spread mooring, with mooring lines attached to extension springs at the basin walls. Each mooring line is instrumented with a load cell for load measurement. The stiffness of these moorings are set such that the global mooring stiffness either replicates that of the full-scale DP controller, or so that the surge and sway natural frequencies are approximately an order of magnitude below the wave frequency, to avoid undue mooring excitation.

In the physical component of this study, a relatively large scale (1:40) self-powered, untethered DP model was exposed to a series of constant wind and irregular wave combined environments, and the mean DP force demand for each trial was used as a baseline for the environmental load on the vessel. The vessel was also moored, unpowered, on two instrumented four-point soft moorings of varied global stiffnesses. One stiffness was chosen to be close to that of the DP controller, and the other such that the natural frequencies were approximately one order of magnitude below the peak wave frequency, as mentioned above. Outputs from load cells on each mooring line were summed, taking into account geometric displacements of the mooring system due to vessel motions, to provide the mean environmental load on the vessel, as measured with soft moorings of common stiffnesses. 


\section{Comparison of DP Performance Prediction Techniques for Scaled Models}

The mean environmental load on the vessel, measured in experiments using the DP and moored models are compared, and conclusions drawn as to sources of variance and how well each experimental result represents actual environmental loading on the vessel. This is done with a view to quantifying the comparative error between common physical DP modeling techniques and determine whether an accurate determination of watch circle performance may be obtained through less complex modeling techniques.

Two side investigations are included in the physical study; the effect of a thruster keepout algorithm and the influence of varied DP control gains on DP stationkeeping performance. Both of these parameters are important in the design of DP systems, and are implemented in various degrees and arrived upon by various methods in all commercial DP systems.(Sørensen, 2011) Limited basin time only permitted one permutation of each experiment, but the results of these changes are presented. A keepout algorithm, which prevents thrusters from pointing directly at neighbouring units, is implemented to reduce destructive thrust interference between thrusters. Keepout effects were quantified by performing bollard pull tests, using the DP system while attached to the moorings to measure the outputted DP thrust for a commanded thrust input. The vessel was also exposed, off mooring, to three orientations of irregular waves with the keepout algorithm active. Measurements of the variance in commanded DP thrust in waves as compared to the experiment condition with no keepout algorithm were compared. Proportional (P) and Derivative (D) controller gains represent the control system stiffness and damping, respectively. These are critical factors in the performance of all PD control based DP 
systems, and may be assigned by using a number of differing tuning procedures (Millan, 2006). For example, assigning large gains may result in very small vessel position error. However, the necessary increase in thruster action to accommodate this will result in increased fuel consumption and mechanical wear (Fossen, 1994)(Sørensen, 2011). As such, there is rarely one optimal answer in the selection of tuning parameters. In this study, an alternate set of proportional and derivative gains are implemented in the DP controller and a series of free offset experiments in surge, sway and yaw were conducted to compare their response characteristics to those of the gains used in the stationkeeping experiments. The vessel was exposed, off mooring, to three orientations of irregular waves with the new gains implemented to measure the variance in commanded DP thrust from the previous gain set.

A series of five regular wave experiments were also completed with full DP control and on each of the mooring systems. The results of these experiments were used to aid in tuning the viscous damping in the numerical simulations through matching of response amplitude operators (RAOs).

\subsection{Numerical Predictions}

Hydrodynamic force and motion prediction software packages are often used in industry to calculate environmental loads on and motions of marine structures. In the design and pairing of Dynamic Positioning systems to floating structures both linear and non-linear analyses are commonly used to calculate environmental forces and vessel motions (Kim, 
2002) (Tannuri, 2006) (Wichers, 1998). Linear theory calculates vessel responses by assuming all waves are small amplitude sine waves. Therefore the hull shape does not change from the static waterplane and a linear relationship is assumed in extrapolated responses. Non-linear theory accounts for changes in waterplane related to ship motions in waves (Pawlowski, 1991). For example, in beam seas the vessel may be excited at both the natural roll period and the wave frequency. For the purpose of this study, the nonlinear seakeeping program MOTSIM was used to simulate the motions of the same hullform and DP control system used in the physical experiments. The numerical vessel model was exposed in MOTSIM to identical wind and wave environments to those used in the experiments, to obtain the mean environmental loads on the vessel. These loads were compared to the physical results with a view to quantify the comparative error between common numerical and physical DP modeling techniques and determine what factors affect the accurate determination of watch circle performance.

The computer code, MOTSIM, is based on potential flow theory, which assumes inviscid flow. As such, viscous damping, especially prevalent in roll, must be accounted for by empirical methods. This trait is common with most commercial hydrodynamic motions software (Pawlowski, 1991) (Peng, 2006). To validate the empirical damping, a series of experiments in regular waves were conducted to produce response amplitude operators (RAO) for the numerical model. These RAOs were compared with those produced by the same method in the physical experiments, and the numerical viscous damping adjusted to match the physical RAOs. 


\section{METHODOLOGY - PHYSICAL EXPERIMENTS}

This section outlines the tools and verification processes utilized in all experiments. These include physical and numerical model-scale moored (stiffness 1 and 2) and DP evaluations. Additional information detailing the experiment facilities and model mass properties is included in Appendix A.

\subsection{Facilities - IOT Offshore Engineering Basin}

Stationkeeping experiments in head, beam and quartering seas with wind and current were completed in the Offshore Engineering Basin (OEB) at the Institute for Ocean Technology (IOT), St. John's, NL. The OEB particulars are given in Table 1.

Table 1: IOT Offshore Engineering Basin (OEB) Particulars

\begin{tabular}{|c|c|}
\hline Particular & Data \\
\hline Length & $62 \mathrm{~m}$ \\
\hline Width & $26 \mathrm{~m}$ \\
\hline Water Depth & $2.5 \mathrm{~m}$ \\
\hline Maximum Basin Wave Height & $1.0 \mathrm{~m}$ \\
\hline Maximum Current Speed & $0.25 \mathrm{~m} / \mathrm{s} @ 2 \mathrm{~m}$ depth \\
\hline Maximum Wind Speed & $5 \mathrm{~m} / \mathrm{s}$ \\
\hline
\end{tabular}

While the OEB water depth can be varied from $0.1 \mathrm{~m}$ to approximately $2.8 \mathrm{~m}$, the water depth was set at $2.5 \mathrm{~m}$ for this experimental research program. The facility is described in detail in Appendix A. 
Comparison of DP Performance Prediction Techniques for Scaled Models

\subsubsection{Basin Layout}

The stationary model position remained fixed within the basin for all experiments. Wind fans were moved as shown in Figures 1 and 2 to create head or beam winds. Waves were calibrated for three headings using the wave makers as shown in Table 2.

Table 2: Wave Maker Utilization

\begin{tabular}{|c|c|}
\hline Wave Heading & Wave Makers in Operation \\
\hline Head & South \\
\hline Quartering & South and West \\
\hline Beam & West \\
\hline
\end{tabular}

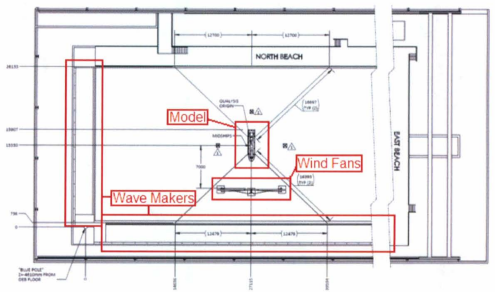

Figure 1: Basin Layout, Head Wind Configuration 


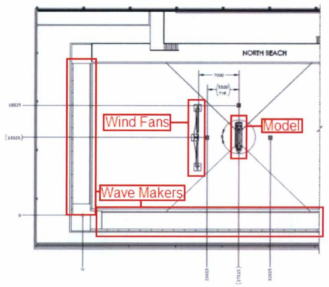

Figure 2: Basin Layout, Beam Wind Configuration

\subsection{Vessel Model}

\subsubsection{Hull}

The instrumented vessel model was constructed to a scale of 1:40 $(\lambda=40)$ based on a simplified geometry 99,000t drill ship. Vessel particulars are outlined in Table 3. The vessel is shown in Figure 3. 


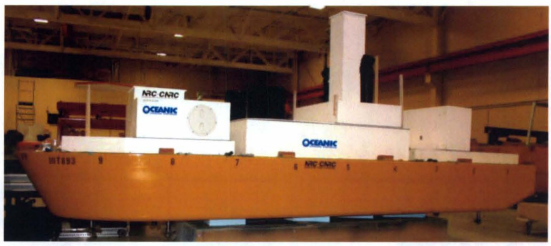

Figure 3: Hull and Topsides

Table 3: Vessel Particulars

\begin{tabular}{|c|c|c|}
\hline Particular & $\begin{array}{c}\text { Full Scale } \\
\text { (SW) }\end{array}$ & $\begin{array}{c}\text { Model Scale } \\
(\mathbf{F W} ; \boldsymbol{\lambda}=\mathbf{4 0} \text { ) }\end{array}$ \\
\hline Length Overall & $206 \mathrm{~m}$ & $5.150 \mathrm{~m}$ \\
\hline Length, WL & $202 \mathrm{~m}$ & $5.053 \mathrm{~m}$ \\
\hline Maximum Beam & $45 \mathrm{~m}$ & $1.125 \mathrm{~m}$ \\
\hline Design Draft & $12 \mathrm{~m}$ & $0.300 \mathrm{~m}$ \\
\hline Design Static Trim & $0.0^{\circ}$ & $0.0^{\circ}$ \\
\hline Design Displacement & 99843 tonnes & $1522 \mathrm{~kg}$ \\
\hline Wetted Surface Area & $13282 \mathrm{~m}^{2}$ & $8.301 \mathrm{~m}^{2}$ \\
\hline
\end{tabular}

\subsubsection{Load Condition}

For all experiments, the model was ballasted to a displacement and trim, corresponding to a full scale draft of $12 \mathrm{~m}$. The model was loaded on draft, not displacement, and draft was matched to a marked waterline. 
Comparison of DP Performance Prediction Techniques for Scaled Models

The model VCG and pitch gyradii were set using a swing frame in air, prior to final ballasting in water. Kzz was assumed to be the same as Kyy. An inclining experiment was performed in water to obtain the as-tested transverse metacentric height (GMt).

\subsubsection{Propulsion Equipment}

Vessel propulsion was provided by six, $360^{\circ}$ azimuthing z-drives driving four-bladed Kaplan style propellers, shown in Figure 4. The propellers were $5 \mathrm{~m}$ (full-scale) diameter machined acrylic with shaftlines located $5.2 \mathrm{~m}$ below the keel. Stock thruster units were used, which do not directly model those typically found on a drillship of this size.

Thruster locations in vessel coordinates are listed in Table 4 with $\mathrm{X}$ reference transom and $\mathrm{Y}$ reference centerline.

Table 4: Thruster Locations (model scale)

\begin{tabular}{|c|c|c|}
\hline Thruster & X Location MS (m) & Y Location MS (m) \\
\hline 1 & 4.572 & 0.0 \\
\hline 2 & 4.0 & -0.33 \\
\hline 3 & 4.0 & 0.33 \\
\hline 4 & 1.213 & 0.0 \\
\hline 5 & 0.641 & -0.33 \\
\hline 6 & 0.641 & 0.33 \\
\hline
\end{tabular}




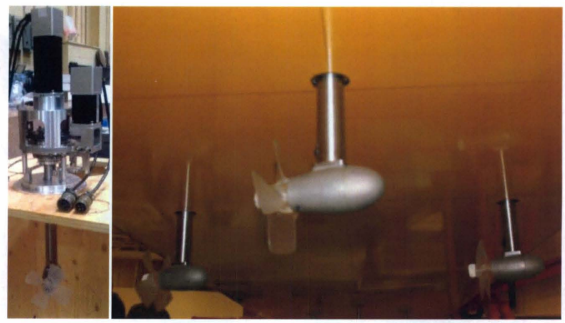

Figure 4: Four-bladed z-drive units

Bollard, (zero speed) thrust experiments were performed using the stiffness 2 mooring (particulars in section 4.6.4.4) to obtain thruster performance curves. These experiments were performed individually for each thruster, which yielded the following coefficients:

$$
\begin{aligned}
& T_{1}=0.0343 *(R P S)^{2} \\
& T_{2}=0.0358 *(R P S)^{2} \\
& T_{3}=0.0340 *(R P S)^{2} \\
& T_{4}=0.0345 *(R P S)^{2} \\
& T_{5}=0.0399 *(R P S)^{2} \\
& T_{6}=0.0386 *(R P S)^{2}
\end{aligned}
$$

Equation 1

Equation 2

Equation 3

Equation 4

Equation 5

Equation 6

Where $T_{n}$ represents the thrust developed by thruster $n$ in Newtons (N) for a given propeller speed RPS in revolutions per second. 


\subsection{Data Acquisition}

All instrumentation was calibrated prior to experiments using the on-board vessel data acquisition system and/or shore-based data acquisition systems. Data was acquired at $50 \mathrm{~Hz}$ with a low pass filter of $10 \mathrm{~Hz}$ applied to all signals unless otherwise specified. The DP Digital Control server updated and transmitted thruster commands at $20 \mathrm{~Hz}$.

\subsection{Instrumentation}

Moored and DP experiments were conducted at three wave headings in irregular waves, with current and wind, to assess second order wave response. Five frequencies of bow quartering regular waves were also evaluated to aid in calibration of future numerical simulations.

For all stationkeeping experiments, a Qualisys ${ }^{\mathrm{TM}}$ optical tracking system was used to determine motions of the vessel. Measured motions were then translated to station 5, centerline at the waterline $(2.53 \mathrm{~m}, 0.0 \mathrm{~m},-0.3 \mathrm{~m} \mathrm{MS})$.

Waves were calibrated using an array of capacitance probes to measure the wave heights. One probe was located at tank centre and three others were located $5.5 \mathrm{~m}$ (tank measurements) to port, starboard and aft of station 5, centerline. During the experiments with the hull, the probe at the centre of the tank was removed. Table 5 outlines the instrumentation used. 
Comparison of DP Performance Prediction Techniques for Scaled Models

Table 5: Instrumentation List - Stationkeeping Experiments

\begin{tabular}{|c|c|c|}
\hline Measurement & Instrumentation & Units \\
\hline DP Set Point X, Y, Heading & DP Digital Output & $\mathrm{m}, \mathrm{deg}$ \\
\hline Surge, Sway, Yaw Thrust Demands & DP Digital Output & $\mathrm{N}, \mathrm{N} . \mathrm{m}$ \\
\hline LF Surge, Sway, Yaw Position Estimates & DP Digital Output & $\mathrm{m}, \mathrm{deg}$ \\
\hline HF Surge, Sway, Yaw Position Estimates & DP Digital Output & $\mathrm{m}, \mathrm{deg}$ \\
\hline LF Surge, Sway, Yaw Velocity Estimates & DP Digital Output & $\mathrm{m} / \mathrm{s}, \mathrm{deg} / \mathrm{s}$ \\
\hline HF Surge, Sway, Yaw Velocity Estimates & DP Digital Output & $\mathrm{m} / \mathrm{s}, \mathrm{deg} / \mathrm{s}$ \\
\hline Pod Shaft Speeds & DP Digital Output & $\mathrm{rps}$ \\
\hline Pod Angles & DP Digital Output & $\mathrm{deg}$ \\
\hline X, Y, \& Z- Acceleration & Crossbow & $\mathrm{g}$ \\
\hline Roll, Pitch and Yaw Rate & Crossbow & $\mathrm{deg} / \mathrm{s}$ \\
\hline Model Position X, Y \& Z & Qualisys & $\mathrm{m}$ \\
\hline Model Roll, Pitch \& Heading & Qualisys & $\mathrm{deg}$ \\
\hline 3x Wave Elevations & Capacitance Wave Probes & $\mathrm{m}$ \\
\hline 4x Mooring Line Loads & Button Type Load Cell & $\mathrm{N}$ \\
\hline Above Water Video Cameras (x 2) & \multicolumn{2}{c}{} \\
\hline
\end{tabular}

\subsubsection{Wind Speed Calibration}

Wind speed was calibrated using an anemometer placed at Stn. 5, centerline of the model's equilibrium position (tank centre). The control voltage of the bank of wind fans was increased over seven steps, while measuring wind velocity in the calibration location. The control voltage corresponding to the desired wind speed was extrapolated from the generated relationship.

\subsection{DP System}

The six thruster DP system employs an uncoupled MIMO PID controller with a Kalman filter. The Kalman filter separates second order and first order (low frequency and high frequency) motions. The second-order position and velocity estimates from the filter are 
used as the feedback signal for the DP controller. A least-squares thrust allocation algorithm is used to convert the control force into azimuth angles and thrust magnitudes for individual thrusters. A control schematic is shown in Figure 5.

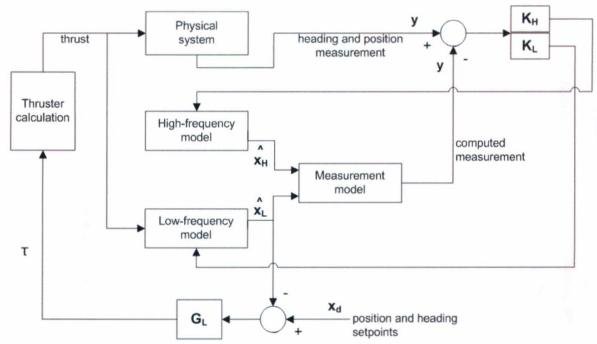

Figure 5: DP Control System Structure, Modified from Saelid (1983)

In the above figure, $G_{L}$ represents the low-frequency feedback gains (proportional and derivative). Terms $K_{H}$ and $K_{L}$ are the high and low-frequency Kalman gains, respectively, and $x_{d}-\hat{x}_{L}$ represents the low frequency position and velocity with respect to the position set points in surge, sway and yaw. Slow motions caused by $2^{\text {nd }}$-order wave, wind, current and thruster forces are represented in the Low-frequency (LF) model. Wave frequency motions due to $1^{\text {st }}$-order wave interaction are accounted for in the High- 
Comparison of DP Performance Prediction Techniques for Scaled Models

frequency (HF) model. Only low-frequency components are included in the feedback, as wave frequency disturbances are of too high magnitude and frequency to compensate with reasonable thrust action.

The control law for these experiments is written as: (adapted from Fossen, 1994)

$$
\begin{array}{ll}
\tau=G_{L}\left(x_{d}-\hat{x}_{L}\right) & \text { Equation } 7
\end{array}
$$

As shown in Equation 7, the control demand vector $\tau$ is only influenced by the LF motion model $\hat{x}_{L}$ with respect to the stationkeeping set point $x_{d}$. A current model and wind feed forward gain matrix are excluded from the controller used in these experiments.

\subsubsection{Thrust Allocation}

As all thrusters are fully azimuthing, the relationship between control and individual thruster demands are defined as (Millan, 2006):

$$
\tau=T_{a} T_{t h}
$$

Equation 8

Where $\tau$ is the control demand vector, $T_{t h}$ is a vector of thruster demands in Cartesian coordinates,

$$
T_{t h}=\left[T_{1 x} T_{1 y}, \ldots, T_{6 x} T_{6 y}\right]^{T}
$$

Equation 9

and $T_{a}$ is the thruster allocation matrix,

$$
T_{a}=\left[\begin{array}{ccccc}
1 & 0 & & 1 & 0 \\
0 & 1 & \ldots & 0 & 1 \\
l_{1 y} & l_{1 x} & & l_{6 y} & l_{6 x}
\end{array}\right]
$$


The bottom row in $T_{a}$ contains lever arm distances from each thruster to the vessel CG in meters. For example, in this experiment $l_{1 y}=0.0$ and $l_{1 x}=\left(X_{1}-L C G\right)=2.156$.

Individual thruster demands are found by solving for $T_{\text {th }}$ using the Moore Penrose generalized inverse:

$$
T_{t h}=\tau\left(T_{a}^{*} T_{a}\right)^{-1} T_{a}^{*}
$$

Equation 11

Where $T_{a}^{*}$ is the conjugate transpose of $T_{a}$.

This formulation provides a least-squares solution for $T_{t h}$, the result is however unbiased to physical thruster limitations such as deliverable power, ramp rates or thruster interactions. For the purpose of these experiments, the individual thruster magnitudes were capped at $20 \mathrm{~N}$. Methods for programming thruster dynamics are presented in Fossen (1994), but were not implemented for this comparison study.

\subsubsection{Low-Frequency Model}

The low frequency velocities were estimated by the following linear model:

$$
M \dot{v}_{L}+D v_{L}=\tau_{L}+w_{L} \quad \text { Equation } 12
$$

Where $v_{L}$ is the LF velocity vector, $\tau_{L}$ is the control force vector, and $w_{L}$ is a vector of zero-mean Gaussian white noise describing unmodeled dynamics and disturbances (Fossen, 1994). Note that at the time of these experiments, the IOT DP controller did not contain a LF current model; therefore no integral effect was present in the state estimate. As such, mean environmental forces manifested as mean physical offsets from the DP set point approximately proportional to the force denominated by the P-gain. 
Comparison of DP Performance Prediction Techniques for Scaled Models

$$
M=\left[\begin{array}{ccc}
m-X_{\dot{u}} & 0 & 0 \\
0 & m-Y_{\dot{v}} & 0 \\
0 & 0 & I_{z}-N_{r}
\end{array}\right] \quad D \cong 0 \text { (for stationkeeping) } \quad \text { Equation 13 }
$$

The inertia matrix, $M$ implemented in the DP controller at this phase of design was absent of the off-axis yaw-sway, sway-yaw coupling terms. Damping $D$ was not included for stationkeeping experiments as the velocity was assumed to be very close to zero.

\subsubsection{High-Frequency Model}

The HF vessel motions are excited by $1^{\text {st }}$-order wave forces. These forces are modeled by three harmonic oscillators with damping to improve robustness. The HF motion spectrum is represented by the following linear approximation (Fossen, 1994):

$$
h(s)=\frac{K_{w} s}{s^{2}+2 \varepsilon w_{0} s+w_{0}^{2}}
$$

\section{Equation 14}

where $K_{w}$ is generally chosen around the peak frequency of the sea state, and $\varepsilon$ is the relative damping ratio, the choice of which determines the how tightly filtered the $\mathrm{HF}$ components are around $K_{w}$. For these experiments, $\varepsilon$ was set to 0.1 and 0.01 for irregular and regular seas, respectively. The amount of HF components transmitted into the feedback loop is governed by the controller design parameter $w_{0}$. The HF vessel motion is described by a set of three differential equations of the form:

$$
\begin{array}{lr}
\dot{\beta}_{i}=\alpha_{H} & \text { Equation 15 } \\
\dot{\alpha}_{H}=-2 \varepsilon w_{0} \alpha_{H}-w_{0}{ }^{2} \beta_{\alpha}+w_{\alpha} & \text { Equation 16 }
\end{array}
$$


Comparison of DP Performance Prediction Techniques for Scaled Models

for $\alpha=x, y, \varphi$ where $\dot{\alpha}_{H}$ and $\alpha_{H}$ are state vectors of velocity and acceleration, and position and velocity, respectively, in surge, sway and yaw, and $w_{a}$ are Gaussian white noise processes. The HF wave model is:

$$
\begin{array}{ll}
\dot{x}_{H}=A_{H} x_{H}+E_{H} w_{H} & \text { Equation } 17
\end{array}
$$

Where $\boldsymbol{x}_{H}=\left[\beta_{x}, \beta_{y}, \beta_{\varphi}, x_{H}, y_{H}, \varphi_{H}\right]^{T}, \boldsymbol{w}_{H}=\left[w_{x}, w_{y}, w_{z}\right]^{T}$ with obvious choices of $\boldsymbol{A}_{H}$ and $\boldsymbol{E}_{H}$ (Fossen, 1994).

The HF model is used solely in the separation of high and low frequency motion components. It plays no role in the calculation of the control demand vector.

\subsection{Experimental Program (Testing Matrix)}

The complete primary experimental program is shown in Table 6 . The experiments were developed to provide comparable cases in each of the two experimental configurations and to provide a suitably wide range of environmental variables to exercise the numerical and experimental approaches. 
Table 6: Experimental Program Matrix

\begin{tabular}{|c|c|c|c|}
\hline Wave Type & Wave Parameter & Wave Direction & Wind Direction \\
\hline Irregular & JONSWAP & Head Sea & - \\
\hline Irregular & JONSWAP & Head Sea & Head Wind \\
\hline Irregular & JONSWAP & Head Sea & Beam Wind \\
\hline Irregular & JONSWAP & Quartering Sea & - \\
\hline Irregular & JONSWAP & Quartering Sea & Head Wind \\
\hline Irregular & JONSWAP & Quartering Sea & Beam Wind \\
\hline Irregular & JONSWAP & Beam Sea & - \\
\hline Irregular & JONSWAP & Beam Sea & Head Wind \\
\hline Irregular & JONSWAP & Beam Sea & Beam Wind \\
\hline Regular & R1 & Quartering Sea & - \\
\hline Regular & R2 & Quartering Sea & - \\
\hline Regular & R3 & Quartering Sea & - \\
\hline Regular & R4 & Quartering Sea & - \\
\hline Regular & R5 & Quartering Sea & - \\
\hline
\end{tabular}

In addition some preparatory experiments were required to set up the main experiments.

These are described in the following sections.

\subsubsection{Roll, Pitch and Mooring Decays}

To obtain the natural periods in roll and pitch for the model, and surge, sway and yaw for the moorings, the model was excited in the direction of interest and permitted to oscillate. Oscillatory motions were captured by Qualisys and the periods were calculated by mean crossing analysis. Each decay was repeated three times and an average taken of the results. Decay Results are presented in Appendix A. 
Comparison of DP Performance Prediction Techniques for Scaled Models

\subsubsection{Mooring Excursions}

Global mooring stiffnesses in surge and sway were verified using excursion trials. Force was applied to the model via a single line and load cell attached midway between the mooring connection points. Excursion distance over a series of force increments was recorded using Qualisys.

\subsubsection{DP Mooring Excursions}

DP excursions were conducted to assess the global relationship between commanded DP force and outputted bollard force when utilizing all thrusters in surge and sway. One particular area of interest was the effect of keepout zone logic in the thrust allocation algorithm on these excursion results.

DP excursion experiments were conducted with the model attached to the less compliant soft mooring (Stiffness 2). The sway demand forces were manually changed in fixed increments and the model was permitted to reach equilibrium at each increment. Bollard force was calculated by resolving the mooring forces measured by the mooring load cells.

\subsubsection{Stationkeeping Experiments}

\subsubsection{Experimental Matrix}

Each of the physical evaluation techniques (Mooring Stiffness 1, Mooring Stiffness 2, and DP) were evaluated over the same series of environments, as shown in Table 7. Detailed parameters of each environment are outlined in section 4.6.4.2. 
Comparison of DP Performance Prediction Techniques for Scaled Models

Table 7: Irregular Wave Experiment Matrix

\begin{tabular}{|c|c|}
\hline Wave Direction & Wind Direction \\
\hline Head Sea & - \\
\hline Head Sea & Head Wind \\
\hline Head Sea & Beam Wind \\
\hline Quartering Sea & - \\
\hline Quartering Sea & Head Wind \\
\hline Quartering Sea & Beam Wind \\
\hline Beam Sea & - \\
\hline Beam Sea & Head Wind \\
\hline Beam Sea & Beam Wind \\
\hline
\end{tabular}

\subsubsection{Environments}

Detailed parameters of each environment referenced in section 4.6.4.1 are shown in Tables 8 \& 9. The wind speed, wave height and peak wave period were selected to model a Beaufort Scale Sea State 5.

Table 8: Irregular Waves

\begin{tabular}{|c|c|c|c|c|c|c|c|}
\hline Spectrum & $\begin{array}{c}\text { FS } \\
\text { Wave } \\
\text { Hs (m) }\end{array}$ & $\begin{array}{c}\text { FS } \\
\text { Wave } \\
\text { Tp (s) }\end{array}$ & Gamma & $\begin{array}{c}\text { MS } \\
\text { Wave } \\
\text { Hs (m) }\end{array}$ & $\begin{array}{c}\text { MS } \\
\text { Wave } \\
\text { Tp (s) }\end{array}$ & $\begin{array}{c}\text { FS Basin } \\
\text { Time } \\
\text { (hours) }\end{array}$ & $\begin{array}{c}\text { MS } \\
\text { Basin } \\
\text { Time } \\
\text { (mins) }\end{array}$ \\
\hline JONSWAP & 3.66 & 9.7 & 3.3 & 0.092 & 1.534 & 3 & 28.46 \\
\hline
\end{tabular}

Table 9: Wind

\begin{tabular}{|c|c|c|}
\hline Wind Heading (deg) & $\begin{array}{c}\text { FS Wind Velocity } \\
(\mathrm{kts})\end{array}$ & $\begin{array}{c}\text { MS Wind Velocity } \\
(\mathbf{m} / \mathbf{s})\end{array}$ \\
\hline Head $(0)$, Beam $(90)$ & 22 & 1.79 \\
\hline
\end{tabular}


Comparison of DP Performance Prediction Techniques for Scaled Models

\subsubsection{Soft Mooring Parameters - Stiffness 1}

Mooring Stiffness 1 was chosen to have a similar global stiffness to the proportional DP control gains. Using $95 \mathrm{~N} / \mathrm{m}$ extension springs; the global mooring stiffnesses are shown in Table 10.

Table 10: Mooring Stiffness 1

\begin{tabular}{|c|c|c|}
\hline $\begin{array}{c}\text { MS Surge } \\
\text { Stiffness } \\
(\mathbf{N} / \mathbf{m})\end{array}$ & $\begin{array}{c}\text { MS Sway } \\
\text { Stiffness } \\
(\mathbf{N} / \mathbf{m})\end{array}$ & $\begin{array}{c}\text { MS Yaw } \\
\text { Stiffness } \\
(\mathbf{N m} / \mathbf{d e g})\end{array}$ \\
\hline 177 & 203 & 22.6 \\
\hline
\end{tabular}

\subsubsection{Soft Mooring Parameters - Stiffness 2}

Mooring Stiffness 2 was chosen as a typical soft mooring; the global stiffnesses place the natural surge, sway and yaw periods approximately one order of magnitude above the peak wave period (of Sea State 5), to avoid mooring excitation. Using 295N/m extension springs; the global mooring stiffnesses are shown in Table 11:

Table 11: Mooring Stiffness 2

\begin{tabular}{|c|c|c|}
\hline $\begin{array}{c}\text { MS Surge } \\
\text { Stiffness } \\
(\mathbf{N} / \mathbf{m})\end{array}$ & $\begin{array}{c}\text { MS Sway } \\
\text { Stiffness } \\
(\mathbf{N} / \mathbf{m})\end{array}$ & $\begin{array}{c}\text { MS Yaw } \\
\text { Stiffness } \\
(\mathbf{N m} / \mathbf{d e g})\end{array}$ \\
\hline 541 & 619 & 68.9 \\
\hline
\end{tabular}

\subsubsection{Dynamic Positioning Parameters}

Although adjustment of gains according to changes in environment may improve controller performance, a fixed set of Proportional and Differential DP gains were used for all experiments. The P-gain was set such that $100 \%$ of available thrust is applied when the position error is equal to the maximum diameter of the watch circle. The D-gain 
was then varied experimentally to provide the desired level of damping, depending on application. High derivate action provides a slower response with less overshoot of target. The gains used for the comparison experiments are shown in Table 12, with response plots shown in Section 6.4.

Table 12: DP Control Gains

\begin{tabular}{|c|c|c|}
\hline Axis & MS P-Gain & MS D-Gain \\
\hline Surge & $150.0 \mathrm{~N} / \mathrm{m}$ & $427.2 \mathrm{Ns} / \mathrm{m}$ \\
\hline Sway & $151.4 \mathrm{~N} / \mathrm{m}$ & $980.6 \mathrm{Ns} / \mathrm{m}$ \\
\hline$\psi$ & $13.6 \mathrm{Nm} / \mathrm{deg}$ & $100.0 \mathrm{Nms} / \mathrm{deg}$ \\
\hline
\end{tabular}

As the variable of interest for the study was not station holding capability, but rather mean control force, wind feed-forward control was not used. The wind force was additive in the controller demand once the vessel reached equilibrium. Current force was accounted for manually by changing the DP set point to bring the vessel back on station; it was therefore also an additive controller demand once the vessel reached equilibrium.

\section{METHODOLOGY - NUMERICAL STUDY}

A time-domain ship motion program, MOTSIM, was used to numerically predict vessel motions and environmental loads. It solved the rigid body equations of motions for a floating body in large waves. The hydrodynamic forces are computed by a scattering potential method. The Froude-Krylov force is computed at each time step based on the instantaneous wetted surface and body position. The program requires a panelized representation of the ship hull, superstructure and deck. For this, CAD is used to segment 
Comparison of DP Performance Prediction Techniques for Scaled Models

the model surface into quadrilateral or triangular panels. Mass properties of the vessel, such as mass, centre of gravity, metacentric height and moments of inertias, were input to be equal to those in the physical model. The six-axis vessel motions, forces and moments were output. For the purpose of this study, calculated motions were transmitted to the DP control module used in the physical experiments. This module then returned the surge and sway forces, and yaw moment, at each time step, as would be exerted by the DP thrusters. An overview of the order of operations is presented in Figure 6. A detailed mathematical description of the program theory is beyond the scope of this paper, but is available in Pawlowski (1991), with further applications in Peng (2006). 
Three right-handed coordinate systems are employed: space-fixed (coincides with the undisturbed water surface), steady moving (moves at a steady forward speed), and ship-fixed (origin at the midship section, intersecting the longitudinal plane of symmetry on the caim water surface when the ship is at rest)

Equations of ship motions are defined, which include the angular velocities about the ship fixed axes and passing through the CG, the generalized ship mass matrix, the moment of inertia matrix of the ship, and the external forces on the ship (restoring forces, non-linear

Froude-Krylov forces, non-linear hydrodynamic scattering forces, viscous forces, hull maneuvering forces, the thruster forces, and wind forces). In DP stationkeeping, viscous forces, thruster forces and wind forces can have a significant influence on motions in certain conditions. Empirical models have been developed to approximate their effects

The computation of the hydrodynamic forces is based on the weak scatter hypothesis. The incoming wave which interacts with the ship is assumed to be high and the disturbance induced by the moving ship in the wave is considered to be of smaller magnitude than the wave. The weak scatter hypothesis applies when the ship moves compliantly with the waves. In the computation of scattering forces, the fluid is assumed to be incompressible and the flow is irrotational. The fotal velocity potential satisfies the Laplace equation.

The kinetic and dynamic free surface, as well as the bottom boundary conditions are defined

,

Based on the weak scatter hypothesis, the velocity potential is split into incident wave potential and velocity potential (scattering potential) components

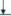

The velocity field can be approximated by a linear combination of orthogonal modes In accordance with the modal potential method, the modes are given by normal shape functions. The hull of the ship is divided into narrow strips or sections vertically, and modes are defined on the strips. In the linear approximation, each mode contributes a component to the scatter potential at every frequency

From the Bernouli equation, the pressure on the wefted surface can be computed
from the scattering potential. The direction of the force is normal to the hull surface. from the scattering potential. The direction of th

The modal diffraction force is calculated as a function of frequency, taking into account added mass and damping coefficients for the given modes. $\checkmark$

The force in time domain is determined by computing the added mass at infinite frequency and the Impulse Response Function (IRF) and then by resolving the velocity field into modal components.

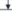

The flow at the hull surface is characterized by the amplitudes of the modal potentials. These amplitudes are determined so as to satisfy the hull boundary condition.

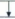

The Froude-Krylov forces and restoring forces are computed on the instantaneous wetted surface of the hull under the incident wave profile.

Figure 6: MOTSIM Operations Overview, compiled from Pawlowski (1991) and Peng (2006) 


\subsection{Data Analysis and Reduction}

During all experiments, online analysis was completed during the experiments to ensure proper response of the instrumentation and to assess the validity of the data measured by each transducer. This was done by first examining the time histories of each data channel to check for abnormalities and then by calculating the basic statistics. Results were also compared to data measured during previous runs. Unless otherwise stated, all data was acquired at a sample rate of $50 \mathrm{~Hz}$ and a $10 \mathrm{~Hz}$ low pass filter was applied. For all acquired data channels, time histories were analyzed to produce basic summary statistics for each time trace. This data included: minimum, maximum, and mean values, along with standard deviations.

\subsection{Response Amplitude Operators}

Response amplitude operators (RAOs) are a representation of vessel response per unit wave height for linear displacements, and angle amplitude over wave slope for rotational displacements, evaluated over a series of wave frequencies. Bow quartering regular wave experiments were conducted at five wave heights and frequencies (giving a constant nominal wave slope of 0.05 ) to obtain RAO curves for the vessel response in surge, sway, yaw, heave pitch and roll. The vessel was evaluated numerically using MOTSIM over identical conditions to verify empirical viscous damping formulations. RAO results are presented in Appendix B. 
Comparison of DP Performance Prediction Techniques for Scaled Models

The RAO results, as calculated from both physical experiments and numerical simulations are shown graphically in Appendix B - Figures 17-21. Mass properties (moment of inertias, center of gravity and metacentric heights) were set equal to those in the physical model. In order to match the Roll RAO, small virtual bilge keels, $0.005 \mathrm{~m}$ MS thick, were added to the MOTSIM model. This is to account for the viscous damping that provides a large proportion of the physical roll damping, and is not modeled in inviscid codes. MOTSIM has no form of external roll damping correction so viscous roll damping may only be accommodated through the addition of bilge keels. The bilge keels were the only modification made to the hull parameters of the numerical model. The numerical (MOTSIM) RAOs show good trend correlation to those obtained in the physical experiments. Surge, sway and yaw motions centered around the peak irregular wave period of $4.1 \mathrm{rad} / \mathrm{s}$ are most relevant to the performance of these comparison experiments. Physical modeling generated slightly higher motion response in nearly all conditions.

Overall the agreement between the RAOs calculated and those measured indicates that the numerical method and the experimental method should agree in terms of predicted hydrodynamic forces. 
Comparison of DP Performance Prediction Techniques for Scaled Models

\subsection{Thrust Allocation Keepout Algorithm}

Keepout zones are a common addition to thrust allocation algorithms in full-scale DP systems. Keepout algorithms specify a range or ranges of azimuth angles that thrusters cannot occupy. This is generally to prevent thrusters from directing their wash into neighbouring thrusters and thereby decreasing their net thrust. (Sørensen, 2011)

A moored sway excursion and a set of irregular wave experiments were run to quantify the effect. Keepout zones were implemented such that the thruster groups at the bow and the stern would not direct thrust within $+/-15$ degrees of diagonally aligned or athwartship thrusters. Interaction between bow and stern thruster groups was not considered, as the distance between the groups was thought to have been sufficiently large that they would not be susceptible to thrust interaction. The results of the sway offsets with and without the keepout algorithm implemented are shown in Figure 7, with the Resultant Mooring Force being the force measured by the mooring load cells. 


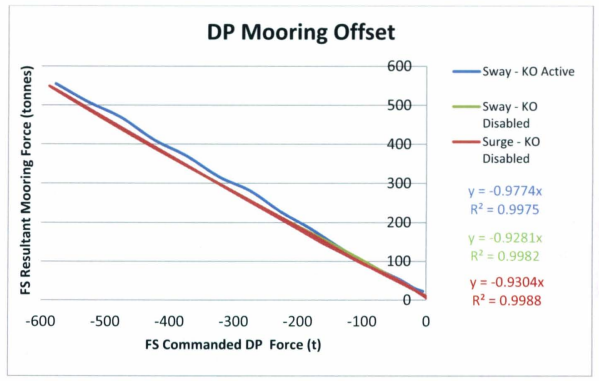

Figure 7: Effect of Keepout Algorithm on Bollard Thrust

The model was exposed to irregular waves in head, quartering and beam headings to observe the effect of keepout logic on stationkeeping forces and position error. The results of these experiments are presented in Table 13 with graphical results in Appendix C. Position standard deviation (SD) is included as a measure of stationkeeping performance, where similar forces with higher SD indicates higher occurrence of position error in the control action. These evaluations were completed in a later session in the basin with newly acquired bollard data for each thruster implemented in the controller, instead of the corrected data which was used for the earlier analysis. The bollard data was directly implemented in the later session to affirm the primary session data corrections. Also, upon post analysis of the initial stationkeeping experiments, a 0.3 degree yaw offset 
Comparison of DP Performance Prediction Techniques for Scaled Models

was discovered in the Qualisys configuration for all moored and unmoored comparisons.

This offset was removed for the purpose of these comparisons, so the results are not directly comparable to the stationkeeping results presented in Section 5.5.

Table 13: Effect of Keepout Logic on Stationkeeping Force and Position Error

\begin{tabular}{|c|c|c|c|c|c|c|}
\cline { 2 - 7 } \multicolumn{1}{c|}{} & \multicolumn{4}{c|}{ Stationkeeping Force } & \multicolumn{2}{c|}{ Position Standard Deviation } \\
\cline { 2 - 7 } \multicolumn{1}{c|}{} & $\begin{array}{c}\text { DP w/ KO } \\
\text { Active }\end{array}$ & $\begin{array}{c}\text { DP w/ KO } \\
\text { Disabled }\end{array}$ & DP w/ KO Active & $\begin{array}{c}\text { DP w/ KO } \\
\text { Disabled }\end{array}$ \\
\cline { 2 - 7 } & MS (N) & FS (t) & MS (N) & FS (t) & FS (m) & FS (m) \\
\hline Head Sea & 3.2 & 21 & 2.9 & 19 & 0.54 & 0.48 \\
\hline $\begin{array}{c}\text { Quartering } \\
\text { Sea }\end{array}$ & 13.5 & 88 & 14.7 & 96 & 1.65 & 1.73 \\
\hline Beam Sea & 27.6 & 180 & 30.5 & 199 & 4.41 & 4.48 \\
\hline
\end{tabular}

\subsection{DP Tuning}

Offset experiments were completed to quantify performance of the DP gains used in the comparative experiments. In addition, a second set of gains were implemented with "sharper" response, and evaluated in waves to provide a comparison for the effect of DP tuning on mean stationkeeping loads and position error. The second gain condition is referred to as DP', comparisons are shown in Table 14.

Table 14: DP and DP' Gain Comparison

\begin{tabular}{|c|c|c|c|c|}
\cline { 2 - 5 } \multicolumn{1}{c|}{} & \multicolumn{2}{c|}{ DP } & \multicolumn{2}{c|}{ DP' } \\
\hline Axis & P-Gain & D-Gain & P-Gain & D-Gain \\
\hline Surge & $150.0 \mathrm{~N} / \mathrm{m}$ & $427.2 \mathrm{Ns} / \mathrm{m}$ & $40.5 \mathrm{~N} / \mathrm{m}$ & $669.9 \mathrm{Ns} / \mathrm{m}$ \\
\hline Sway & $151.4 \mathrm{~N} / \mathrm{m}$ & $980.6 \mathrm{Ns} / \mathrm{m}$ & $151.4 \mathrm{~N} / \mathrm{m}$ & $427.2 \mathrm{Ns} / \mathrm{m}$ \\
\hline$\psi$ & $13.6 \mathrm{Nm} / \mathrm{deg}$ & $100.0 \mathrm{Nms} / \mathrm{deg}$ & $13.5 \mathrm{Nm} / \mathrm{deg}$ & $67.0 \mathrm{Ns} / \mathrm{deg}$ \\
\hline
\end{tabular}


Comparison of DP Performance Prediction Techniques for Scaled Models

Response characteristics of the offset experiments are shown in Figures 8, 9 \& 10. These experiments were performed in calm water with the vessel unmoored. The set point was altered by $0.2 \mathrm{~m}$ in surge and sway, and 5 degrees in yaw and the vessel position response measured using Qualysis. Surge response was altered from over damped, slow with zero overshoot error, to more critically damped, fast response with some overshoot and minimal oscillation. Sway response was modified slightly to reduce oscillation, both cases are essentially critically damped with similar response. Yaw response was modified from over-damped, slow response with zero overshoot error to slightly under-damped with fast response. Some ringing was present in both yaw conditions, this was thought to be attributed to the slight instability of the simplified wave filter when operating in calm water.
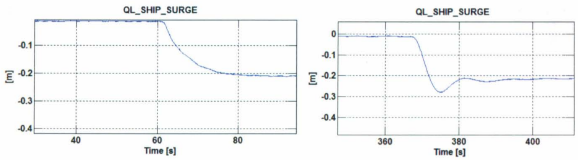

Figure 8: Surge response of as-experimented DP tuning (left) and alternate tuning DP' (right) 

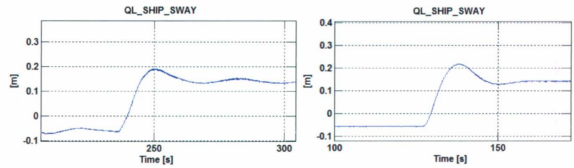

Figure 9: Sway response of as-experimented DP tuning (left) and alternate tuning DP' (right)
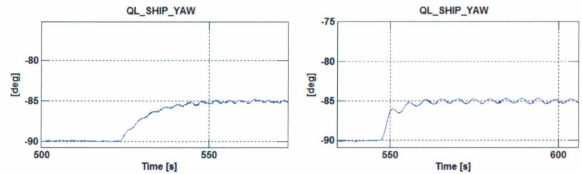

Figure 10: Yaw response of as-experimented DP tuning (left) and alternate tuning DP' (right)

The model was exposed to irregular waves in head, quartering and beam headings to observe the effects of the altered tuning parameters on stationkeeping forces and position error. The results of these experiments are presented in Table 15 with graphical results in Appendix C. Position standard deviation (SD) is included as a measure of stationkeeping performance, where similar forces with higher SD indicates higher occurrence of position error in the control action. The keepout logic discussed in section 5.3 was active for both DP and DP' experiments. These evaluations were also completed in a later session in the basin with the newly acquired thruster bollard data implemented in the controller, instead of values corrected by analysis. As in the previous case, upon post analysis of the initial 
Comparison of DP Performance Prediction Techniques for Scaled Models

stationkeeping experiments, a 0.3 degree yaw offset was discovered in the Qualisys configuration for all moored and unmoored comparisons. This offset was removed for the purpose of these comparisons, so the results are not directly comparable to the stationkeeping results presented in Section 5.5.

Table 15: Effect of DP Tuning on Stationkeeping Force and Position Error

\begin{tabular}{|c|c|c|c|c|c|c|}
\cline { 2 - 7 } \multicolumn{1}{c|}{} & \multicolumn{4}{c|}{ Stationkeeping Force } & \multicolumn{2}{c|}{ Position Standard Deviation } \\
\cline { 2 - 7 } \multicolumn{1}{c|}{} & \multicolumn{2}{c|}{ DP } & \multicolumn{2}{c|}{ DP' } & DP & DP' \\
\cline { 2 - 7 } & MS (N) & FS (t) & MS (N) & FS (t) & FS (m) & FS (m) \\
\hline Head Sea & 3.2 & 21 & 2.4 & 16 & 0.54 & 0.85 \\
\hline $\begin{array}{c}\text { Quartering } \\
\text { Sea }\end{array}$ & 13.5 & 88 & 13.4 & 87 & 1.65 & 1.94 \\
\hline Beam Sea & 27.6 & 180 & 26.0 & 169 & 4.41 & 3.87 \\
\hline
\end{tabular}

\subsection{Physical Stationkeeping Evaluations}

Physical stationkeeping experiments were performed for each configuration (Mooring Stiffness 1, Mooring Stiffness 2, and DP) over the series of environments described in Section 4.6.4.2. Mean stationkeeping forces and station standard deviation for each condition are displayed in Table 16 (Note: HS: head seas; QS: quartering seas; BS: beam seas). The vessel under DP control in irregular waves is shown in Figure 11. 


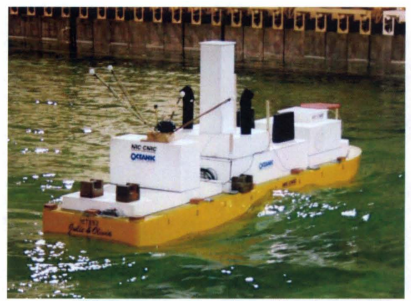

Figure 11: Image of the vessel under DP control in waves

Stationkeeping forces can be seen to be generally lower in the moored systems than those measured using the full DP vessel. Position standard deviation agreement between like wave headings and stationkeeping methodology shows excellent correlation of vessel motion between experiment configurations. Agreement between position standard deviation of like wave headings and stationkeeping methodologies shows excellent correlation of vessel motion between experiment configurations. 
Comparison of DP Performance Prediction Techniques for Scaled Models

Table 16: Full-Scale Mean Stationkeeping Forces (tonnes)

\begin{tabular}{|c|c|c|c|c|c|c|c|}
\multicolumn{2}{c|}{} & \multicolumn{3}{c|}{$\begin{array}{c}\text { FS Stationkeeping } \\
\text { Force (t) }\end{array}$} & \multicolumn{3}{c|}{$\begin{array}{c}\text { FS Position Standard } \\
\text { Deviation (m) }\end{array}$} \\
\cline { 3 - 9 } \multicolumn{2}{c|}{} & HS & QS & BS & HS & QS & BS \\
\hline \multirow{3}{*}{ Head Wind } & Stiffness 1 & 30 & 61 & 189 & 0.7 & 2.2 & 5.1 \\
\cline { 2 - 8 } & Stiffness 2 & 30 & 62 & 182 & 0.3 & 1.0 & 3.1 \\
\cline { 2 - 8 } & DP & 31 & 70 & 191 & 0.8 & 1.5 & 4.1 \\
\hline
\end{tabular}

\begin{tabular}{|c|c|c|c|c|c|c|c|}
\hline Beam Wind & Stiffness 1 & 35 & 88 & 219 & 0.7 & 2.2 & 5.1 \\
\cline { 2 - 8 } & Stiffness 2 & 39 & 82 & 218 & 0.3 & 1.1 & 3.3 \\
\cline { 2 - 8 } & DP & 46 & 100 & 230 & 0.9 & 1.5 & 4.1 \\
\hline
\end{tabular}

\begin{tabular}{|c|c|c|c|c|c|c|c|}
\hline \multirow{2}{*}{ w/o Wind } & Stiffness 2 & 14 & 58 & 193 & 0.3 & 1.0 & 3.3 \\
\cline { 2 - 8 } & DP & 19 & 66 & 195 & 0.9 & 1.7 & 4.1 \\
\hline
\end{tabular}

Mooring predictions of stationkeeping force are presented in Table 17 as percentages of the force magnitudes obtained using the full-DP model. Similarly reduced stationkeeping forces can be seen for all moored cases, with percent deviation decreasing and becoming more consistent as the overall loading increases in quartering and beam seas.

Table 17: Mooring Force with respect to DP Force

\begin{tabular}{|c|c|c|c|c|}
\cline { 3 - 5 } \multicolumn{2}{c|}{} & \multicolumn{3}{|c|}{$\begin{array}{c}\% \text { Stationkeeping Force w.r.t. } \\
\text { DP Force }\end{array}$} \\
\cline { 3 - 5 } \multicolumn{2}{c|}{} & HS & QS & BS \\
\hline \multirow{2}{*}{ Head Wind } & Stiffness 1 & $-4 \%$ & $-13 \%$ & $-1 \%$ \\
\cline { 2 - 5 } & Stiffness 2 & $-3 \%$ & $-11 \%$ & $-5 \%$ \\
\hline
\end{tabular}

\begin{tabular}{|c|c|c|c|c|}
\hline Beam Wind & Stiffness 1 & $-23 \%$ & $-11 \%$ & $-5 \%$ \\
\cline { 2 - 5 } & Stiffness 2 & $-14 \%$ & $-18 \%$ & $-5 \%$ \\
\hline
\end{tabular}

\begin{tabular}{|c|c|c|c|c|}
\hline w/o Wind & Stiffness 2 & $-24 \%$ & $-13 \%$ & $-1 \%$ \\
\hline
\end{tabular}


Comparison of DP Performance Prediction Techniques for Scaled Models

\subsection{Numerical Stationkeeping Evaluations}

Numerical stationkeeping experiments were performed for the DP configuration over the series of environments described in section 4.6.4.2. Mean stationkeeping forces and station standard deviation for Numerical DP, Physical DP and Physical Mooring Stiffness 2 are displayed in Table 18. A rendered view of the panelized hull is shown in Figure 12.

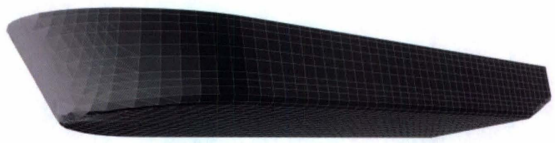

Figure 12: Panelized Hull Render

Stationkeeping forces calculated using MOTSIM were consistently lower than those measured using physical DP or moorings. Position standard deviation shows that stationkeeping performance of the numerical model is between that measured for the physical DP and that measured on the moorings, for all but the beam seas condition.

Table 18: FS Mean Stationkeeping Forces (tonnes)

\begin{tabular}{|c|c|c|c|c|c|c|c|}
\hline & \multicolumn{3}{|c|}{$\begin{array}{l}\text { FS Stationkeeping Force } \\
\text { (t) }\end{array}$} & \multicolumn{3}{|c|}{$\begin{array}{c}\text { FS Position Standard } \\
\text { Deviation (m) }\end{array}$} \\
\hline & & HS & QS & BS & HS & QS & BS \\
\hline \multirow{3}{*}{$\begin{array}{l}\text { w/o } \\
\text { Wind }\end{array}$} & Numerical DP & 3 & 57 & 158 & 0.8 & 1.3 & 5.7 \\
\hline & Physical DP & 19 & 66 & 195 & 0.9 & 1.7 & 4.1 \\
\hline & Physical S2 & 14 & 58 & 193 & 0.3 & 1 & 3.3 \\
\hline
\end{tabular}


Comparison of DP Performance Prediction Techniques for Scaled Models

Physical DP and Stiffness 2 mooring predictions of stationkeeping force are presented in Table 19 as percentages of the force magnitudes obtained using the Numerical DP model. Reduced stationkeeping forces can be seen for all moored cases. The large percentage magnitude decrease in the head seas condition is only on the order of $2 \mathrm{~N} \mathrm{MS}$, which is very small, variation of this size is to be expected in such experiments.

Table 19: Mooring Force with respect to DP Force

\begin{tabular}{|c|c|c|c|c|}
\cline { 3 - 4 } \multicolumn{2}{c|}{} & \multicolumn{3}{c|}{$\begin{array}{c}\% \text { Stationkeeping Force } \\
\text { w.r.t. Numerical DP Force }\end{array}$} \\
\cline { 3 - 5 } \multicolumn{2}{c|}{} & HS & QS & BS \\
\hline \multirow{2}{*}{$\begin{array}{c}\text { w/o } \\
\text { Wind }\end{array}$} & Physical DP & $-86 \%$ & $-13 \%$ & $-19 \%$ \\
\cline { 2 - 5 } & Physical S2 & $-80 \%$ & $-1 \%$ & $-18 \%$ \\
\hline
\end{tabular}

\section{DISCUSSION OF RESULTS}

\subsection{Comparison of Physical Stationkeeping Forces}

The graphical results of the stationkeeping force analysis are contained in Appendix D. These results in general show that predictions of stationkeeping force are higher when acquired using the full-DP model. Also, the time traces for all experiments show that on the soft mooring and similarly soft DP system, the peak loads are reduced, as compared to those on the stiffness 2 mooring, and these correspond to higher peak position deviations from station.

Referencing Table 16, the trend toward lower force measured by the mooring versus DP holds in all conditions. Second order, slowly varying environmental forces should remain 
Comparison of DP Performance Prediction Techniques for Scaled Models

consistent over all measurement types, which leads to the hypothesis that external factors are decreasing the efficiency of the DP output. Figures 13 \& 14 display lower deviations from station on the stiffness 2 mooring, as would be expected for the higher spring rate. The lower position deviations on the stiffness 2 mooring correspond to higher peak forces. However, mean environmental load measurement is shown to be essentially independent of mooring stiffness.
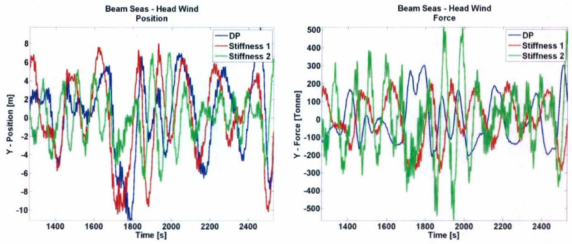

Figure 13: FS Beam Seas Head Wind Position and Force
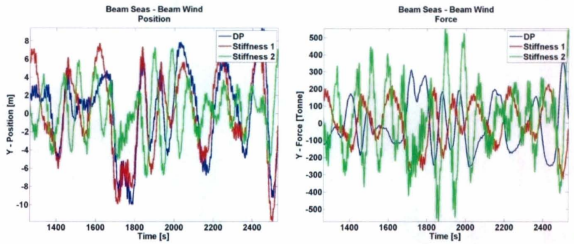

Figure 14: FS Beam Seas Beam Wind Position and Force 
A number of phenomena affect force prediction when using the closed loop DP system. The DP thrusters were not configured to measure unit force, however relative velocity can decrease the outputted thrust of a propeller for a given revolution rate. Moratelli et al. (2009) found that non-axial flow velocity, such as that imposed by azimuthing action or roll, pitch and yaw motions generally decrease thruster efficiency. As such, in a closed loop DP system with only propeller speed related to bollard performance as force feedback, reduced propeller thrust manifests as artificially inflated stationkeeping demand forces. The system will demand a force from the propulsion system to correct a position error, and if the thrusters output less thrust per revolution rate than prescribed in the bollard curves, the system will not respond as expected, and will demand more thrust to correct this. If thrust were measured at each thruster and not assumed from a lookup curve, the summed output thrust would likely be much closer to that measured by the moorings. Additionally, the model scale results in Table 20 show the loads on the vessel in head seas, head wind and no wind conditions to be very small in magnitude. This can lead to large relative measurement uncertainty in both the DP system and the mooring system - measurement uncertainty is discussed further in Section 6.5. The percent variance results in Table 17 show convergence between moored and DP results for larger forces seen in beam waves. 
Table 20: Model Scale Stationkeeping Force Components

\begin{tabular}{|c|c|c|c|c|c|c|c|}
\hline & \multicolumn{3}{|c|}{$\begin{array}{l}\text { MS Stationkeeping Surge } \\
\text { Force (N) }\end{array}$} & \multicolumn{3}{|c|}{$\begin{array}{c}\text { MS Stationkeeping Sway } \\
\text { Force (N) }\end{array}$} \\
\hline & & HS & QS & BS & HS & QS & BS \\
\hline \multirow{3}{*}{ Head Wind } & S1 & -4.5 & -4.9 & -1.1 & -0.1 & -8.0 & -28.9 \\
\hline & S2 & -4.5 & -4.1 & -1.3 & -1.1 & -8.6 & -27.9 \\
\hline & DP & -4.5 & -4.7 & -3.1 & -1.4 & -9.7 & -29.1 \\
\hline \multirow{4}{*}{ Beam Wind } & & & & & & & \\
\hline & S1 & -2.8 & -2.8 & -0.4 & -4.7 & -13.3 & -33.6 \\
\hline & S2 & -2.8 & -2.8 & 0.0 & -5.4 & -12.2 & -33.4 \\
\hline & DP & -2.8 & -2.9 & -1.4 & -6.4 & -15.0 & -35.2 \\
\hline \multirow{3}{*}{ w/o Wind } & & & & & & & \\
\hline & S2 & -2.1 & -2.3 & 0.4 & -0.7 & -8.6 & -29.6 \\
\hline & DP & -2.8 & -2.7 & -1.3 & -0.8 & -9.8 & -29.9 \\
\hline
\end{tabular}

The consequence of this discrepancy in delivered force is that a correction is required if these measurements are to be used as indicators of the net environmental force. However as an indicator of the DP system performance they may be a more accurate indicator of the actual system demand as all the thruster degradation effects would also exist at full scale although the scaling may not be correctly accounted for.

\subsection{Comparison of Numerical Stationkeeping Forces}

Stationkeeping forces were calculated using MOTSIM time-domain numerical simulation with the same DP control algorithm and environmental parameters as the physical experiments. The graphical results of the stationkeeping force analysis are contained in Appendix E. These results and those in Table 18 show that the numerical simulations yielded consistently lower forces. 
Though the numerical simulation was under DP control, it exhibited forces more closely matched with the moored physical model. As discussed in Section 6.1, there are many losses associated with measured thrust in the physical DP system: thruster interaction, Coanda effect, and relative flow velocity. The numerical DP model uses the same control gains and Kalman filter as the physical model. However, it does not take into account thrust losses associated with propulsion dynamics such as thruster interactions with the fluid, thrust effects on the vessel. It also does not take into account thrust degradation due to interaction between thrusters. The numerical model therefore applies $100 \%$ of demanded thrust directly to the vessel. This is much more efficient than is possible in the physical case, and thus will serve to reduce the required force measured in the closedloop controller. Table 21 displays the small variances in surge force from those measured with physical DP and moorings. The larger sway forces show good correlation, though are a slight underestimate as previously discussed.

Table 21: MS Numerical Stationkeeping Force Components

\begin{tabular}{|c|c|c|c|c|c|c|c|}
\hline & \multicolumn{3}{|c|}{$\begin{array}{c}\text { MS Stationkeeping Surge } \\
\text { Force (N) }\end{array}$} & \multicolumn{3}{|c|}{$\begin{array}{c}\text { MS Stationkeeping Sway } \\
\text { Force (N) }\end{array}$} \\
\hline & & HS & QS & BS & HS & QS & BS \\
\hline \multirow{3}{*}{$\begin{array}{l}\text { w/o } \\
\text { Wind }\end{array}$} & Numerical DP & -0.4 & 1.2 & 0.7 & 0.0 & -8.7 & -24.2 \\
\hline & Physical DP & -2.8 & -2.7 & -1.3 & -0.8 & -9.8 & -29.9 \\
\hline & Physical S2 & -2.1 & -2.3 & 0.4 & -0.7 & -8.6 & -29.6 \\
\hline
\end{tabular}

To better demonstrate how the propulsive losses are not modeled in the numerical simulation, the MOTSIM mooring application was used to model moorings with equal geometry and stiffness to those used in the physical model for stiffness 1 and stiffness 2 
Comparison of DP Performance Prediction Techniques for Scaled Models

moorings. The full scale stationkeeping force magnitudes are shown in Table 22. It can be seen that there was very little deviation between the numerical mooring and DP results, just as it would be in the physical model if no propulsive losses were present.

Table 22: MS Numerical Mooring Force Comparison

\begin{tabular}{|c|c|c|c|c|c|c|c|}
\hline & \multicolumn{3}{|c|}{$\begin{array}{c}\text { MS Stationkeeping Surge } \\
\text { Force (N) }\end{array}$} & \multicolumn{3}{|c|}{$\begin{array}{c}\text { MS Stationkeeping Sway } \\
\text { Force (N) }\end{array}$} \\
\hline & & HS & QS & BS & HS & QS & BS \\
\hline \multirow{3}{*}{$\begin{array}{c}\text { w/o } \\
\text { Wind }\end{array}$} & Numerical DP & -0.4 & 1.2 & 0.7 & 0.0 & -8.7 & -24.2 \\
\hline & Numerical S1 & -0.8 & 0.8 & 0.5 & -0.1 & -8.7 & -23.8 \\
\hline & Numerical S2 & -0.7 & 1.0 & 0.2 & 0.0 & -8.8 & -24.0 \\
\hline
\end{tabular}

Thus numerical simulations will need to be calibrated to account for the real world inefficiencies of either model scale or full scale thruster units in their positions attached to a realistic hull. These interaction effects may be explored at model scale with interaction experiments using two instrumented thruster units and simulated hull geometries. Such experiments may give an estimation of thrust degradation at reduced cost, for integration into a numerical simulation, when compared to constructing a full physical model.

\subsection{The Effects of Keepout Zones}

In the DP mooring excursion results, the variance in slopes show that the thrust interaction between thrusters $2 \& 3$, and 5 \& 6 account for a $5 \%$ increase in output (measured) sway force. This was a result of the propeller race of the upstream thrusters directing into the propellers of the downstream units. In this condition, the downstream 
propellers operate at a higher intake velocity, which translates to a higher advance coefficient (J-value), resulting in a reduction of the propeller blade loading. Unexpectedly, a similar reduction in thrust was observed in the surge direction. The DP controller was not programmed such that longitudinal keepout zones could be implemented within the time constraints of the physical experiment program. The slopes of the KO Disabled excursion plots in Figure 7 for surge and sway are approximately equal. This shows a $5 \%$ total thrust reduction between longitudinal thruster groups, when compared to the Sway - KO Active condition, with slope -0.977 . One would expect thrusters to experience less interaction longitudinally due to the greater distance between units. However, when the thrusters are oriented to provide thrust in the surge direction, all six thrusters experience interactions, as compared to only four when providing sway thrust. As such, for an equivalent degradation in total thrust, the unit thrust degradation longitudinally is approximately $4 / 6$ that experienced athwartships. Also, Coanda effect on thrust vectoring and frictional losses may be more prevalent in the surge direction, as the thrust has further to travel while in contact with the vessel's hull, as referenced in Moratelli (2009).

When implemented in waves, results in Table 13 show that diagonal and athwartship keepout zones reduced required thruster force by $8 \%$ and $10 \%$ in quartering and beam sea conditions, respectively. The position SDs displayed decreases of $5 \%$ and $2 \%$ for quartering and beam seas, indicating reduced excursion from station as well. Longitudinal keepout was not implemented, so the $0.3 \mathrm{~N}$ MS increase in force observed in 
the beam sea condition may be attributed mostly to experimental repeatability, as global force measurements $<0.5 \mathrm{~N}$, though accounting for $13 \%$ of the measured value in the case of the head sea condition, are in the noise of such experiments.

It is clear that keepout zone implementation has a significant effect and should be implemented at model scale or in numerical models to properly represent the system performance. Keepout zones should be implemented in the same way as intended for the full scale system. If keepout zones have not been explicitly specified at the time of vessel modeling, it would be beneficial to optimize the placements and sizes of the zones through multiple static and wave optimization experiments.

\subsection{The Effects of Altered DP Tuning in Offsets and Waves}

Referencing Table 15, reductions in required stationkeeping force of $24 \%, 1 \%$ and $6 \%$ in Head, Quartering and Beam seas, respectively, were achieved by varying the control gains. The percentage decrease observed in surge seems large; however, as the force magnitude is small $(0.8 \mathrm{~N})$ when compared to the other environments, the experimental error potentially makes up a larger component of the measurement. It could be reliably stated that the performance has improved, but the percent magnitude may be artificially inflated. The quartering sea produced a similar load; however the position SD is $17 \%$ higher, indicating that the combination of surge, sway gain alterations acting in a quartering sea lead to increased motion about station or "looser" control. Reducing the DGain in surge to smooth the critically damped motion yielded a small decrease in 
stationkeeping force, but a relatively large decrease in stationkeeping performance, evidenced by a $56 \%$ increase in position SD.

This brief experimental investigation into the effect of DP gains on stationkeeping force and position holding performance shows that both of these parameters can be notably affected by variations in proportional and derivative control gains. Manufacturers of commercial DP systems hold the tuning of their full-scale systems as a closely guarded trade secret. As such, it would be beneficial to conduct more rigorous optimizations of control gains at model scale to ensure that the manufacturer tuned gains at full-scale will in fact provide the best stationkeeping performance and efficiency in all operation environments.

\subsection{Measurement Uncertainty}

In evaluating the results of these comparisons, it is worthwhile to consider the uncertainty of the measurements. The accuracy expected from measurement transducers varies depending on a number of factors such as load range, location, and camera placement. Uncertainty analysis is broken in to two types of uncertainty, type A and type B. Type A represents experimental error, such as model misalignment, and is evaluated by taking repeated measurements of the same experimental condition. Type B represents base level error that is inherent in each sensor, calibration, data acquisition system, and data analysis. Type A and B uncertainties are combined by their root sum of squares to form the total experimental uncertainty. 
For the purpose of this study, funding only permitted one experiment for each data point. As such, Type A uncertainty could not be accurately assessed for the experiment as a whole, and application of appropriate standards and personnel experience in the preparation of each experiment was relied upon to create an environment which was replicated as consistently as possible. A summary of Type B uncertainties for the primary measurement components of this evaluation is provided in Table 23. The calculations, utilizing methods outlined in ITTC (2008) and JCGM (2008), and calibration plots to support these results are presented in Appendix F. Qualisys uncertainty was taken directly from the manufacturer's specifications.

The uncertainty in DP thrust measurement is not directly quantifiable without instrumented thruster units. The DP Mooring Excursion experiments showed a 93\% and $92.8 \%$ relationship between commanded (measured) and output surge and sway force in the bollard condition. Type B uncertainty analysis was performed on the DP Mooring Excursion experiments, which gives the uncertainty of the aforementioned thrust relationships. 
Comparison of DP Performance Prediction Techniques for Scaled Models

Table 23: Measurement Uncertainties

\begin{tabular}{|c|c|}
\hline Measurement Parameter & $\begin{array}{c}\text { Type B Uncertainty } \\
\left(u_{B}\right)\end{array}$ \\
\hline \multicolumn{2}{|l|}{ Mooring Stiffness 1} \\
\hline Surge Force $(F x)$ & $1.05 \%$ \\
\hline Sway Force $(F y)$ & $1.05 \%$ \\
\hline \multicolumn{2}{|l|}{ Mooring Stiffness 2} \\
\hline Surge Force $(F x)$ & $1.05 \%$ \\
\hline Sway Force $(F y)$ & $1.08 \%$ \\
\hline \multicolumn{2}{|l|}{ DP Bollard Force } \\
\hline Surge Force $(F x)$ & $1.16 \%$ \\
\hline Sway Force $(F y)$ & $1.40 \%$ \\
\hline \multicolumn{2}{|l|}{ Wave Generation } \\
\hline Significant Wave Height $(H s)$ & $1.2 \%$ \\
\hline Peak Wave Period $(T p)$ & $3.6 \%$ \\
\hline \multicolumn{2}{|l|}{ Wind Generation } \\
\hline Wind Speed & $1.56 \%$ \\
\hline \multicolumn{2}{|l|}{ Vessel Motions } \\
\hline Qualisys $^{\mathrm{TM}}$ Translational $(X, Y, Z)$ & $\pm 1 \mathrm{~mm}$ \\
\hline Qualisys ${ }^{\mathrm{TM}}$ Rotational $(\phi, \theta, \psi)$ & $\pm 0.05^{\circ}$ \\
\hline
\end{tabular}

\section{CONCLUSIONS AND FURTHER WORK}

This study conducted a systematic experimental investigation using a 1:40 scale prototype of a simplified 99,000t DP Drill Ship. The effects of keepout zone implementation, DP tuning, and stationkeeping forces collected using physical experimental techniques are presented. A comparison of physical versus numerically generated stationkeeping forces is also covered. The objective of the research was to compare the effect that varied modes of measurement for environmental forces on DP systems have on the resultant measurements. 
The results of the research show that stationkeeping forces measured using soft moorings are less susceptible to dynamic sources of error found in a full-DP model such as thrust reduction due to thruster interactions, varying rotation rate, azimuth speed and vessel motions. Trends found between stationkeeping forces measured on moorings and with DP suggest that decreased thruster efficiency may lead to inflated stationkeeping demand forces caused by the closed loop response of the DP system. Decreased thruster efficiency may be caused by non-axial flow velocity, such as that imposed by azimuthing action or roll, pitch and yaw motions. These thrust degradation effects will often also be present in the full scale system. So the stationkeeping forces measured by an accurately modeled full-DP experiment will likely be closest to the required full scale propulsion output. However, it is important to quantify these effects, so that design components such as thruster geometry and placement, and keepout zones algorithms may be optimized to minimize them. It is for this reason that both moored and full-DP evaluations are useful; moored, to measure environmental loads, and full-DP, to quantify dynamic propulsion losses found in full-scale.

In addition to the stationkeeping comparisons, results from wave experiments and mooring offsets showed that by implementing keepout zones, thereby reducing the interaction between thrusters, delivered sway thrust may be increased by $5 \%$ (static) to $8 \%$ (dynamic). A similar reduction in required thrust was observed in the surge direction. The DP controller was not programmed such that longitudinal keepout zones could be implemented within the time constraints of the physical experiment program. However, 
Comparison of DP Performance Prediction Techniques for Scaled Models

the thrust reduction magnitude evidences similar interaction characteristics between the longitudinal thruster groups. Thus the evidence is that it is important that keepout zones be fully implemented if active DP model tests are used to predict system performance.

In future experiments, it would be beneficial to install force dynamometers on each thruster for measurement of unit force. Ideally, a thruster force feedback loop would be implemented in the motor controllers such that commanded versus unit force error is minimized. As such, further comparison work in the physical modeling field is needed; the DP vessel should be instrumented with thruster force feedback and have a thruster keepout algorithm that encompasses all thruster interaction angles, including longitudinal in order to remove these sources of uncertainty. It must also be understood that some of these effects may be present in the full scale system and thus related increases in required power would not be modeled by a mooring system.

The numerical simulation completed using MOTSIM exhibited forces more closely matched with the moored physical model than that of the physical DP, as shown in Table 21. Thrust losses associated with propulsion dynamics such as thruster interactions with the fluid, thrust effects on the vessel, and thrust degradation due to interaction between thrusters were not accounted for in this code. These simplifications in the numerical simulations resulted in reduced stationkeeping forces. This would provide an overestimate of watch circle performance if used as a sole means of evaluation. In future numerical experiments, an attempt should be made to model physical thrust degradation 
Comparison of DP Performance Prediction Techniques for Scaled Models

effects, by estimating thruster interference zones and hull interaction effects on propeller wash. These inclusions would serve to increase the numerical force predictions to align more so with the physical experiments and the expected performance of real-life systems.

In conclusion, simplified moorings may be relied upon to provide accurate measurement of mean environmental forces acting on a vessel. These results may be used in the selection and sizing of a DP system for installation. However, once a DP system has been selected, the most accurate measure of watch circle performance is a full DP model. This method ensures thrust degradation effects are accounted for, provided it has been configured with accurate thruster and hull geometry and an identical control algorithm. Also, even with fully modeled propulsion, control and hull geometry, thrusters should still be instrumented to measure unit forces to account for dynamic thrust losses and measure correlation between propulsive power and environmental forces.

Non-linear numerical simulation, if not augmented with empirical thrust interaction dynamics, will provide an underestimate of stationkeeping forces. In future software development, this should be accounted for.

A hybrid, moored and full-DP approach is desirable to account for all system dynamics. However, an extensive physical experiment program can be very costly. If budget is not available for a rigorous, hybrid, physical experiment program, a non-linear numerical simulation paired with physical thrust degradation experiments may provide a realistic 
Comparison of DP Performance Prediction Techniques for Scaled Models

system performance prediction for less investment. This investigation has shown that the numerical simulation follows the trends of the physical model, but tends to underestimate mean forces. More comparison work is needed in this field to see if a numerical simulator, augmented with corrected thrust degradation effects, accurately models the physical system.

For further work utilizing reduced scale full-DP apparatus, the control system would benefit from expanding the state estimator to include axis coupling and damping; this would also allow for modeling of transit operations. Also, expansion to include wind feed forward control and current estimation (integral action) would reduce mean position error associated with wind, current and mean second order wave forces. Keepout algorithms should be extended to include fore-aft thruster interaction, which was shown to be significant. The aforementioned modifications, in addition to control strategies such as hybrid control strategy for operations between transit and stationkeeping would better suit the current apparatus to modeling of commercially available DP systems. 
Comparison of DP Performance Prediction Techniques for Scaled Models

\section{REFERENCES}

Aalbers, A. B., \& Merchant, A. A. (1996). Hydrodynamic model testing for closed loop DP assisted mooring. Paper presented at the Proceedings of the Annual Offshore Technology Conference, 2 913-920.

Fossen, T. I. (1994). Guidance and control of ocean vehicles. Chichester: Wiley.

ITTC Recommended Procedures and Guidelines (2005). Floating Offshore Platform Experiments. Testing and Extrapolation Methods Loads and Responses, Ocean Engineering. 7.5-02-07-03.1.

Hermanski, G., Derradji-Aouat, A., Hackett, P. (2001). Uncertainty Analysis Preliminary Data Error Estimation For Ship Model Experiments. Paper presented at the 6th Canadian Marine Hydro-mechanics and Structures Conference.

Hyakudome, T., Nakamura, M., Kajiwara, H., Koterayama, W. (2000). Experimental study on dynamic positioning control for semisubmersible platform. International Journal of Offshore and Polar Engineering, 10, 187-194.

ITTC Recommended Procedures and Guidelines (2005). Laboratory Modelling of Multidirectional Irregular Wave Spectra. Testing and Extrapolation Methods Loads and Responses, Ocean Engineering. 7.5-02-07-01.1.

ITTC Recommended Procedures and Guidelines (2008). Uncertainty Analysis Instrument Calibration. Testing and Extrapolation Methods Loads and Responses, Ocean Engineering. 7.5-01-03-0.1

JCGM - Joint Committee for Guides in Metrology (2008). Evaluation of measurement data - Guide to the expression of uncertainty in measurement. JGCM 100:2008. 
Comparison of DP Performance Prediction Techniques for Scaled Models

Retrieved from: http://www,iso.org/sites/JCGM/GUM/JCGM100/C045315e$\mathrm{html} / \mathrm{C} 045315 \mathrm{e} . \mathrm{html}$ csnumber $=50461$

Kim, H., Hong, S., Hong, S., \& Yoo, W. (2002). Analysis on DP performance of a shuttle tanker with various analysis methods. Paper presented at the Proceedings of ISOPE Pacific/Asia Offshore Mechanics Symposium, 177-182.

Millan, J. P. (2006). Online Discrete Event Control of Hybrid Systems. PhD. Thesis, Memorial University of Newfoundland.

Moratelli Jr., L., Morishita, H., Souza, C.., Da Costa, P., Fonseca, R., \& Tannuri, E. A. (2009). Experimental evaluation of azimuth thruster for tanker scale model with dynamic positioning system. Paper presented at the IFAC Proceedings Volumes (IFAC-PapersOnline), 190-194.

Pawlowski, J., Bass, D. (1991). A Theoretical and Numerical Model of Ship Motions in Heavy Seas. SNAME Transactions. Vol. 99, pp. 319-352.

Peng, H., Doucet, M., Moore, T., Bailey, S. (2006). Numerical Simulation of the Seakeeping Response of a Multi-hull Ship. Paper presented at the Sixteenth International Offshore and Polar Engineering Conference.

Saelid, S., Jenssen, N., Balchen, J. (1983). Design and Analysis of a Dynamic Positioning System Based on The Kalman Filtering and Optimal Control. IEEE Transactions on Automatic Control, 28(3), 331-339.

Sørensen, A. J. (2011). A survey of dynamic positioning control systems. Anmual Reviews in Control, 35(1), 123-136. 
Comparison of DP Performance Prediction Techniques for Scaled Models

Tannuri, E. A., \& Morishita, H. (2006). Experimental and numerical evaluation of a typical dynamic positioning system. Applied Ocean Research, 28(2), 133-146. Retrieved from: www.scopus.com

Tannuri, E.A., Morishita, H.M., Et al. (2009). DP Assisted Offloading Operations in Brazilian Water. Paper presented at the Dynamic Positioning Conference. Retrieved from: http:/www.dynamicpositioning.com/dp2009/operations - tannuri.pdf

Tannuri, E. A., Saad, A. C., \& Morishita, H. M. (2009). Offloading operation with a DP shuttle tanker: Comparison between full scale measurenments and numerical simulation results. Paper presented at the IFAC Proceedings Volumes (IFACPapersOnline), 249-254.

Wheeler, J. (2004). The Dynamic Response of Capacitance Wave Probes. National Research Council Canada, Laboratory Memorandum LM-2004-11.

Wichers, J., Bultema, S., \& Matten, R. (1998). Hydrodynamic research on and optimizing dynamic positioning system of a deep water drilling vessel. Paper presented at the Proceedings of the Anmual Offshore Technology Conference, 4 553-564. 


\section{APPENDIX A}

Additional Physical Modeling Information 


\section{OVERVIEW}

Additional information about the experimental setup and facilities are contained in this appendix.

\section{CO-ORDINATE SYSTEM}

Six-degree-of-freedom motions and rotations were measured with an optical tracking system (Qualisys ${ }^{\mathrm{TM}}$ ) using four markers attached to the prototype. Qualisys ${ }^{\mathrm{TM}}$ is a shorebased optical tracking system that tracks marker targets arranged on the model of interest. The positions of the targets are recorded on six infra-red video cameras. Using rigid body mechanics, motions were translated to the vessel's station 5, centerline, and waterline. Qualisys ${ }^{\mathrm{TM}}$ provided position data $(X, Y, Z, \phi, \theta, \psi)$ for the hull, where the translational vector $(X, Y, Z)$ was in an earth-fixed reference frame, and the angular vector $(\phi, \theta, \psi)$ represented the angles of rotation of the model's primary axes in a body-fixed reference frame.

The positive sense for the $X_{-}, Y_{-}$, and $Z$-axes were forward, to starboard, and down, respectively. Positive moments and rotations were clockwise when looking from the origin along the positive direction of each respective axis. Thus, positive pitch is bow up, positive roll is to starboard, and positive yaw is bow to starboard. Figure 15 illustrates the coordinate system used. 


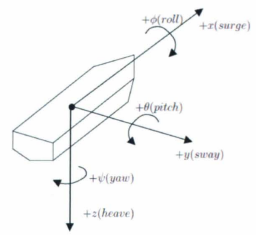

Figure 15: Coordinate System (Millan, 2006)

In general, all experiment procedures used by OCC follow the recommended procedures of the ITTC (ITTC, 2005). Where deviations from such standards are made, the details and reasoning behind such deviations are documented.

\section{VESSEL}

\section{Hull Construction}

The model hull was supplied to OCC pre-fabricated by IOT. It was constructed to a scale of 1:40 $(\lambda=40)$ based on a simplified geometry $99,000 t$ drill ship. The model consisted of

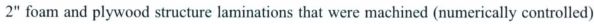
to the geometry of the supplied hull surface. In areas where appendages and outfit equipment were located, Renshape ${ }^{\mathrm{TM}}$ high density foam was inserted to increase the local strength. The model plug was covered with three layers of fiberglass and one layer of Duratec $^{\mathrm{TM}}$ fairing compound, and then was sanded and faired. In the final step, the 
Comparison of DP Performance Prediction Techniques for Scaled Models

model was coated with yellow paint, infused with silica sand, originally intended for use in ice experiments.

\section{Mass Properties}

For all experiments, the model was ballasted to the specified displacement and trim, corresponding to a full scale draft of $12 \mathrm{~m}$. The model was loaded on draft, not displacement, and draft was matched to a marked waterline.

The model was swung in pitch to obtain VCG and pitch gyradii prior to ballasting. Kzz was assumed to be very close to Kyy. An inclining experiment was performed to obtain the as-tested transverse metacentric height (GMt). The pitch swing apparatus is shown in Figure 16. The model mass properties are outlined in Table 24.

Table 24: Mass Properties for Stationkeeping Experiments

\begin{tabular}{|c|c|c|}
\hline Parameter & Full Scale & Model Scale \\
\hline VCG & $12.8 \mathrm{~m}$ & $0.32 \mathrm{~m}$ \\
\hline LCG & $96.64 \mathrm{~m}$ & $2.416 \mathrm{~m}$ \\
\hline$G M_{T}$ & $7.6 \mathrm{~m}$ & $0.19 \mathrm{~m}$ \\
\hline$k_{Y Y}$ & $53.52 \mathrm{~m}$ & $1.338 \mathrm{~m}$ \\
\hline
\end{tabular}




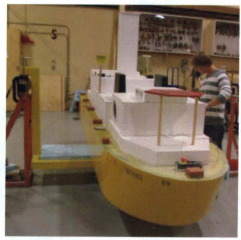

Figure 16: Model Swing (Pitch)

\section{Hull Markings}

The hull was marked with one waterline (at the $12 \mathrm{~m}$ draft) and eleven stations (Station 0 at the AP and Station 10 at the FP).

\section{Natural Periods}

Roll and pitch decays were completed, both on and off moorings, to obtain the natural roll and pitch periods of the vessel. This data is used in conjunction with the mass properties as inputs to the numerical seakeeping model. Model periods are shown in Table 25 . 
Comparison of DP Performance Prediction Techniques for Scaled Models

Table 25: Decay Results

\begin{tabular}{|c|c|c|c|}
\hline & MS (s) & FS (s) & $\begin{array}{c}\text { Linear Damping } \\
\text { (N.s/m) }\end{array}$ \\
\hline Decay & \multicolumn{3}{|c|}{ Free } \\
\hline Roll & 2.0 & 12.4 & 0.0069 \\
\hline Pitch & 1.5 & 9.7 & 0.1269 \\
\hline Decay & \multicolumn{3}{|c|}{ Mooring Stiffness 1} \\
\hline Roll & 2.0 & 12.5 & 0.009 \\
\hline Pitch & 1.5 & 9.7 & 0.1907 \\
\hline Surge & 15.4 & 97.6 & \\
\hline Sway & 15.4 & 97.6 & \\
\hline Yaw & 15.7 & 99.3 & \\
\hline Decay & \multicolumn{3}{|c|}{ Mooring Stiffness 2} \\
\hline Roll & 2.0 & 12.6 & 0.013 \\
\hline Pitch & 1.3 & 8.1 & 0.1714 \\
\hline Surge & 10.5 & 66.5 & \\
\hline Sway & 13.3 & 83.9 & \\
\hline Yaw & 12.1 & 76.6 & \\
\hline
\end{tabular}




\section{FACILITY SPECIFICATIONS}

\section{Specifications:}

\begin{tabular}{|c|c|}
\hline Length & $75 n t$ \\
\hline Wath & $32 \mathrm{~m}$ \\
\hline Max. Water Depth & $3.2 \mathrm{~m}$ \\
\hline Wave Making Systen ipowen & $1800 \mathrm{~kW}$ \\
\hline Max Wave Height (tregilat waves) & $1 \mathrm{~m}$ \\
\hline Max Sig Wave Height dinegular wanes) & $0.5 \mathrm{~m}$ \\
\hline Hange of Waveliengths & $0.5 m$ to $20 m$ \\
\hline Articulation of Wases imodess & $\begin{array}{l}\text { Flapper, Pistor, } \\
\text { Combination }\end{array}$ \\
\hline Wane 5 pectra & $\begin{array}{l}\text { Repular, inegulat, } \\
\text { Bi-modal, } \\
\text { Mutridiectionst }\end{array}$ \\
\hline Curient Speed & $\begin{array}{l}\text { Walee deptl? } \\
\text { Dependent } \\
\text { [0.2msec at } \\
2 \mathrm{~m} \text { depth }\end{array}$ \\
\hline Average Wind Vedocity & $\begin{array}{l}11 \text { mise at im trom fari: } \\
5 \mathrm{~m} \text { sec at } 5 \mathrm{~m} \text { from fan }\end{array}$ \\
\hline
\end{tabular}

tretelent Wind Spersum Mean 5 pee:
- Aistomatic ar Manual Wind Generation Systesn enchudes two movable banks of six fars - each fan having six blades.

$530 \mathrm{~mm}$ diameter, 3hp DC motoci)

- VMS and Wirdoss NT Chentiserver System for Data Acusilion

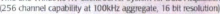

- 32 Channef Dipatal Radio Teiemetry link icoltects data from

modet mounted sersorsh

- 50ooke Mawahle Orathead crane iservices entite basinf

Applications:

- Testing of Mxored Foating Systems or Gavity Base

Structures in Wend Woves and Current

- Testing of Frestunning Settpropetled Ship Models

Tests Performed:

- Scaluceping

- Mariesivering

- Wive Enxrgy Comprsion

- Wine impact toads on Stips or Otshome Structures

- Tow Ota, Set Down and Operation of Otishoie Strictures

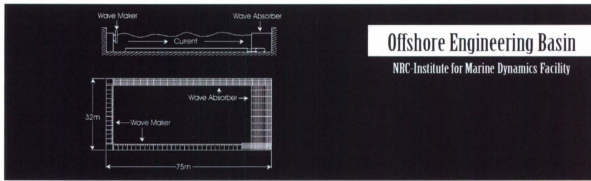

Wind Spectra

Mooted Models

Frentiming Modets

Instrumentation \& Equipment:

- Hydraulixally Actuasted Muatidinectional Wawe Making

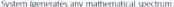
matches time series data within wawe board specs accommodales water depths of $0.1 \mathrm{~m}$ to $3.2 \mathrm{~m}$ useng vertical adjustment

- 168 Computef-controlled Wove Makers in 'T' Confiksuratich

- Flixed and Movatie Passive Wave Absorticer

- Caparitance and Uitrasonic Probos imeasines waves

- Eectromagnetic and Acoustic Flow Meters

- Optical Trackang System Igives simultaneous hiph speed. measutement of poution and orientation of multipie bodies in six degrees of freedoris

- 1000he Aerirculating Curnent System icovers entive baeni

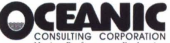

In Canada: 95 Bontwerave Ave. Sulde 40

PO Blox 28009 St pohns Mowhendinad

$$
\text { A1B } 4 \text { NS Conodo }
$$

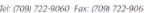
In the United States: 9807 Wothicimne Sedte 30 ?

Houstan Toxas

77042 USA

관 (7) $917-6605$ Fac (713) 917-6806

e man; oceanicaloceoniccorp com wwioceaniccarp cons 


\section{RESPONSE AMPLITUDE OPERATORS}

\section{Experiments}

Quartering regular wave experiments were conducted at five incrementing wave heights and frequencies to obtain RAO curves for the vessel response in surge, sway, yaw, heave pitch and roll. The vessel was evaluated numerically using MOTSIM over identical conditions to verify empirical viscous damping formulations. A description of the regular wave environments is shown in Table 26. Wind was not generated for these experiments.

Table 26: Regular Wave Parameters

\begin{tabular}{|c|c|c|c|c|c|c|c|c|c|}
\hline $\begin{array}{c}\text { Wave } \\
\text { ID }\end{array}$ & $\begin{array}{c}\text { Wave } \\
\text { Category }\end{array}$ & $\begin{array}{c}\text { Wave } \\
\text { Slope }\end{array}$ & $\begin{array}{c}\text { FS } \\
\text { Wave } \\
\mathbf{H s} \\
(\mathbf{m})\end{array}$ & $\begin{array}{c}\text { FS } \\
\text { Wave } \\
\mathbf{T p} \\
\mathbf{( s )}\end{array}$ & $\begin{array}{c}\text { Wave } \\
\text { Heading }\end{array}$ & $\begin{array}{c}\text { MS } \\
\text { Wave } \\
\mathbf{H s} \\
\mathbf{( m )}\end{array}$ & $\begin{array}{c}\text { MS } \\
\text { Wave } \\
\mathbf{T p} \\
(\mathbf{s})\end{array}$ & $\begin{array}{c}\text { FS } \\
\text { Basin } \\
\text { Time } \\
\text { (hours) }\end{array}$ & $\begin{array}{c}\text { MS } \\
\text { Basin } \\
\text { Time } \\
\text { (mins) }\end{array}$ \\
\hline R1 & Regular & 0.02 & 7.72 & 15.68 & $\begin{array}{c}\text { Quartering } \\
(45)\end{array}$ & 0.193 & 2.48 & 31.6 & 5.00 \\
\hline R2 & Regular & 0.02 & 4.92 & 12.59 & $\begin{array}{c}\text { Quartering } \\
(45)\end{array}$ & 0.123 & 1.99 & 31.6 & 5.00 \\
\hline R3 & Regular & 0.02 & 3.44 & 10.50 & $\begin{array}{c}\text { Quartering } \\
(45)\end{array}$ & 0.086 & 1.66 & 31.6 & 5.00 \\
\hline R4 & Regular & 0.02 & 2.52 & 8.98 & $\begin{array}{c}\text { Quartering } \\
(45)\end{array}$ & 0.063 & 1.42 & 31.6 & 5.00 \\
\hline R5 & Regular & 0.02 & 1.92 & 7.84 & $\begin{array}{c}\text { Quartering } \\
(45)\end{array}$ & 0.048 & 1.24 & 31.6 & 5.00 \\
\hline
\end{tabular}

\section{Results}

The RAO results, as calculated from both physical experiments and numerical simulations are shown graphically in Figures 17-21. In both cases the model was unmoored and the DP system was used to hold position. Mass properties (Mass moment of inertias, Centers of gravity and Metacentric heights) were set equal to those in the 
physical model. In order to match the Roll RAO, small virtual bilge keels, $0.005 \mathrm{~m}$ MS thick, were added to the MOTSIM model. This is to account for the viscous damping that provides a large proportion of the physical roll damping, and is not modeled in inviscid codes. Addition of bilge keels were the only modification made to the hull parameters of the numerical model. The numerical (MOTSIM) RAOs show good trend correlation to those obtained in the physical experiments. Surge, sway and yaw motions centered around $T p=4.1 \mathrm{rad} / \mathrm{s}$ are of the most relevance to the performance of these comparison experiments. Physical modeling generated slightly higher motion response in nearly all conditions.

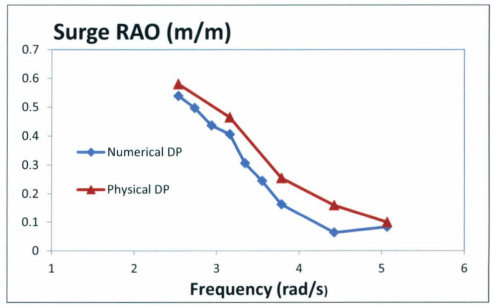

Figure 17: Surge RAO Comparison 


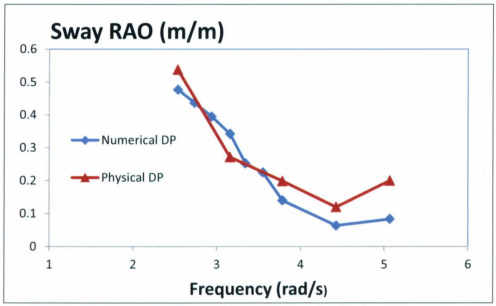

Figure 18: Sway RAO Comparison

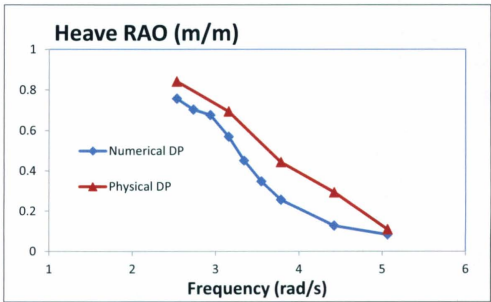

Figure 19: Heave RAO Comparison 


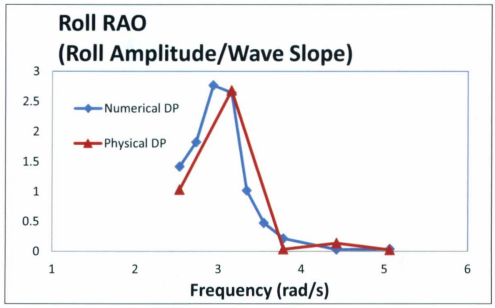

Figure 20: Roll RAO Comparison

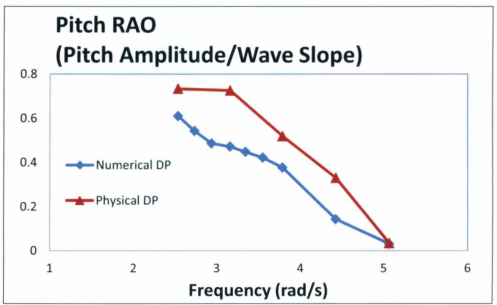

Figure 21: Pitch RAO Comparison 


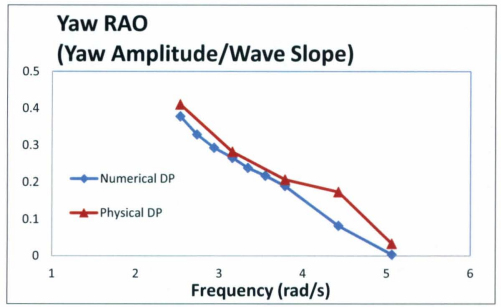

Figure 22: Yaw RAO Comparison 


\section{APPENDIX C}

\section{Graphical Results of DP Algorithm Adjustments}


Comparison of DP Performance Prediction Techniques for Scaled Models

\section{OVERVIEW}

Stationkeeping forces as imparted by the DP system for DP and Keepout (KO) algorithm adjustment experiments are presented in model-scale, polar format. DP denotes the tuning used during the stationkeeping experiments, whereas DP' denotes the alternate tuning discussed in Section 5.4. Keepout algorithm adjustments are discussed in Section 5.3 .

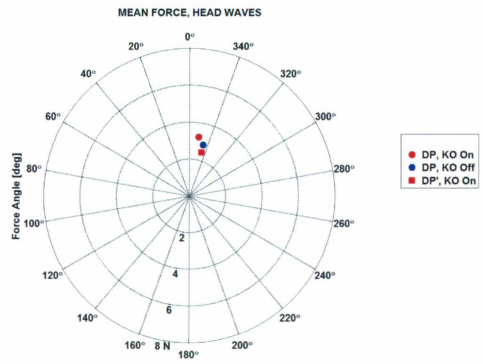


Comparison of DP Performance Prediction Techniques for Scaled Models
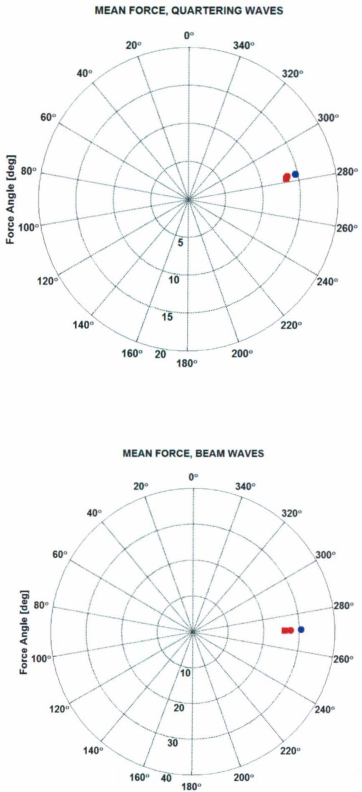
Comparison of DP Performance Prediction Techniques for Scaled Models

STANDARD DEVIATION POSITION, HEAD WAVES

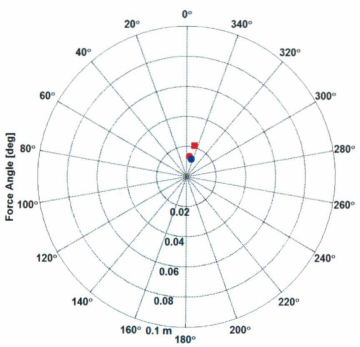

STANDARD DEVIATION POSITION, QUARTERING WAVES

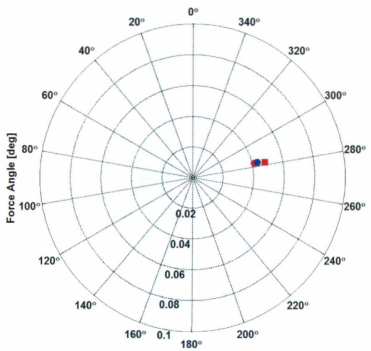


Comparison of DP Performance Prediction Techniques for Scaled Models

STANDARD DEVIATION POSITION, BEAM WAVES

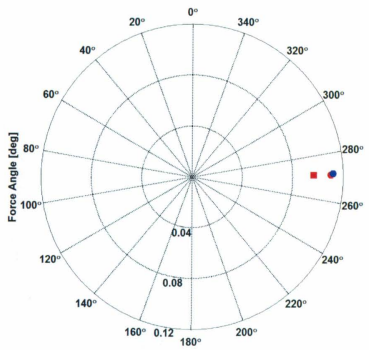

- DP, Ko On

- DP, KO Off

- DP', KO On

\section{C-5}




\section{APPENDIX D}

\section{Graphical Physical Stationkeeping Results}


Comparison of DP Performance Prediction Techniques for Scaled Models

\section{OVERVIEW}

Stationkeeping forces as imparted by the moorings and DP system for moored and DP experiments, respectively, are presented in model-scale, polar and full-scale time series formats. Moored experiments are denoted by their respective stiffnesses.
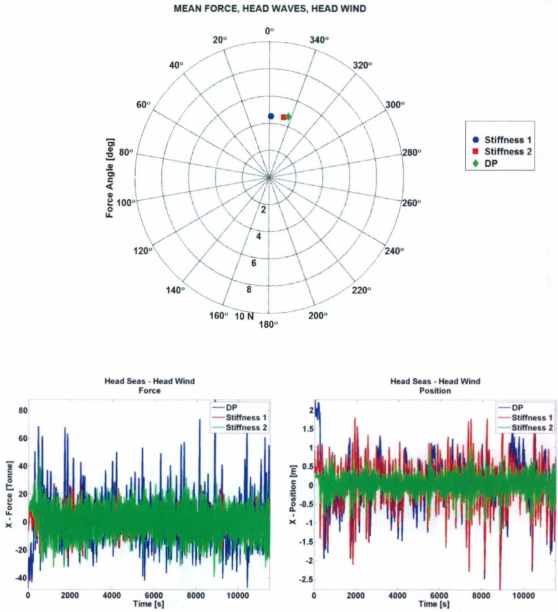
Comparison of DP Performance Prediction Techniques for Scaled Models

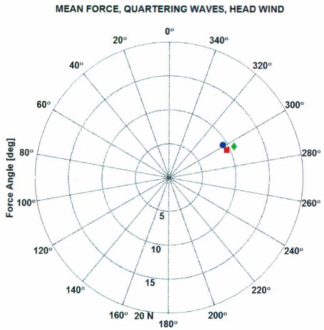

- Stiffness 1

Stiffness 2

- DP
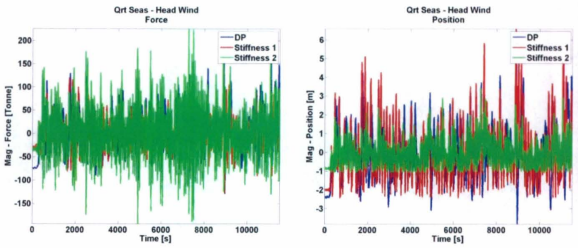

D-3 
Comparison of DP Performance Prediction Techniques for Scaled Models
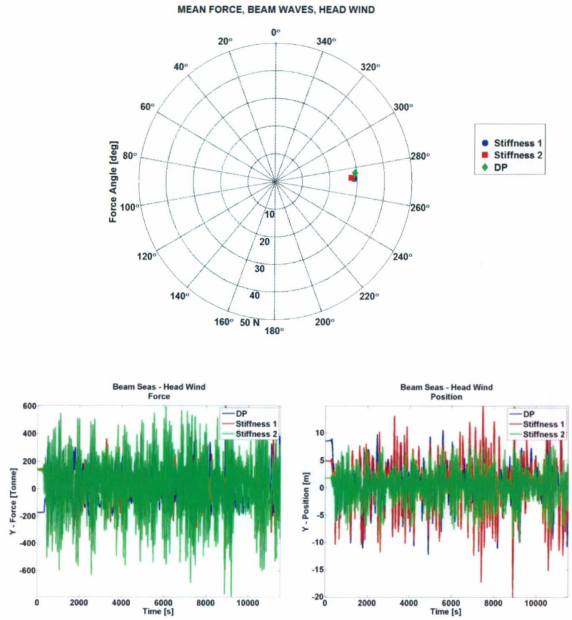
Comparison of DP Performance Prediction Techniques for Scaled Models
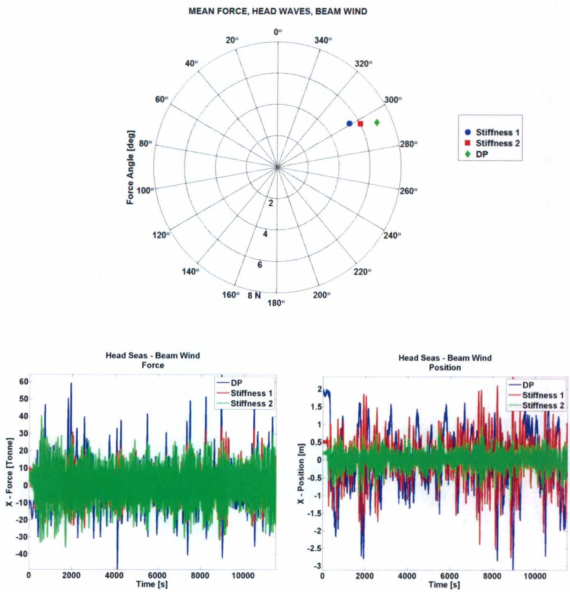

D-5 
Comparison of DP Performance Prediction Techniques for Scaled Models
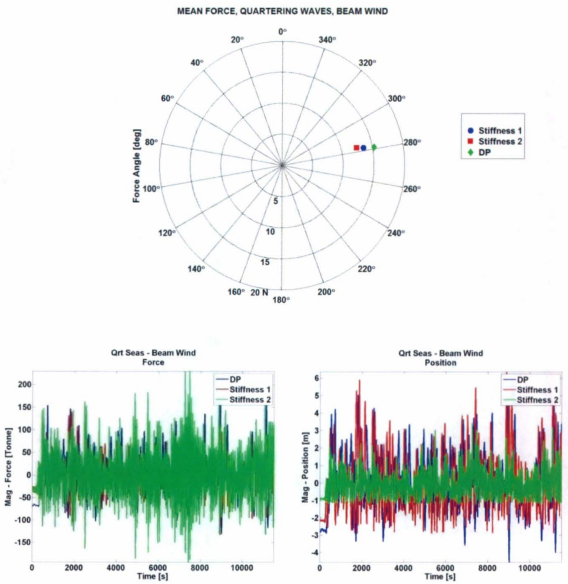
Comparison of DP Performance Prediction Techniques for Scaled Models

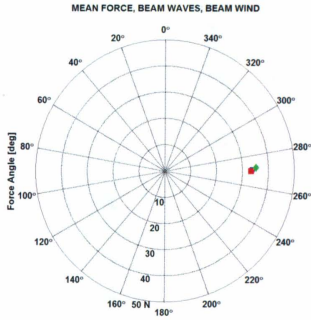

- Stiffness 1

Stiffness 2

Beam Seas - Beam Wind
Force

Beam Seas - Beam Wind
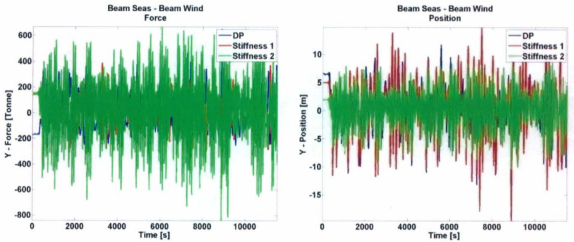

D-7 
Comparison of DP Performance Prediction Techniques for Scaled Models
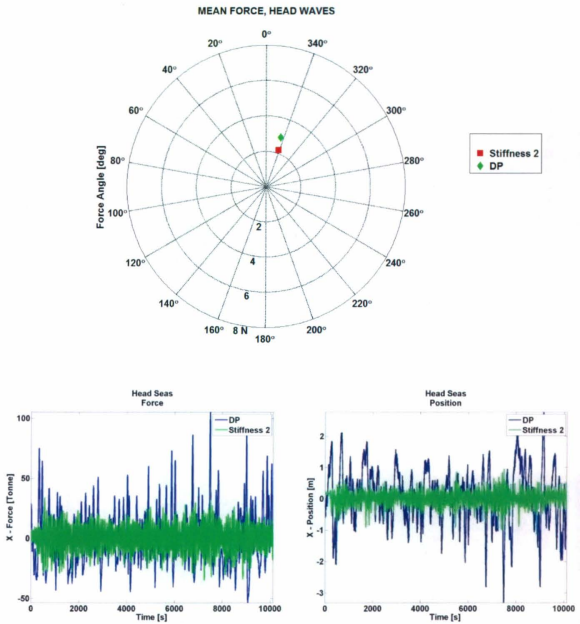
Comparison of DP Performance Prediction Techniques for Scaled Models
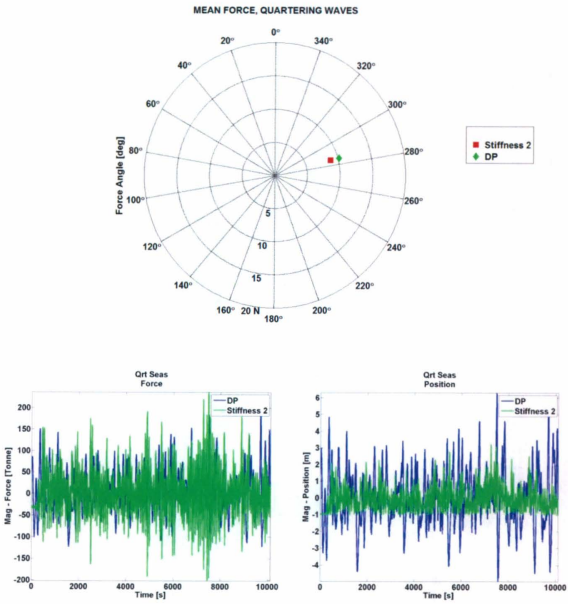

D-9 
Comparison of DP Performance Prediction Techniques for Scaled Models
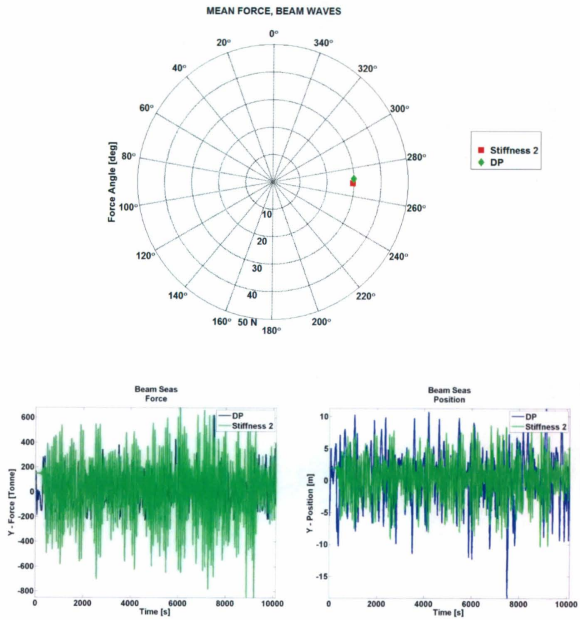

D-10 


\section{APPENDIX E}

\section{Graphical Numerical Stationkeeping Results}


Comparison of DP Performance Prediction Techniques for Scaled Models

\section{OVERVIEW}

Time series force and position plots are presented for the numerical seakeeping results in Figures $23,24 \& 25$, overlaid with the physical DP data. In quartering seas, the vector magnitudes of position and force are displayed, labeled Pos_Resolve and Force_Resolve, respectively. It can be seen that, though the means are similar, there is much greater variation in load in the physical model. Though the physical load variations appears to be at a higher frequency, this is purely an illusion of higher amplitude force corrections; these forces are not first order. As discussed in Section 6.1, this is due to the closed loop control compensation for thruster losses in the physical model.
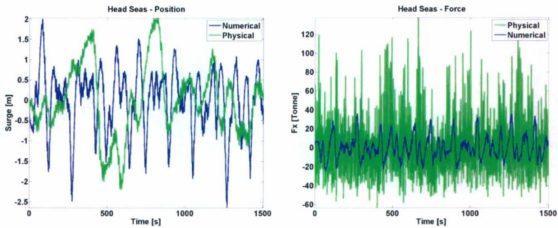

Figure 23: Numerical Head Seas Position and Force 
Comparison of DP Performance Prediction Techniques for Scaled Models
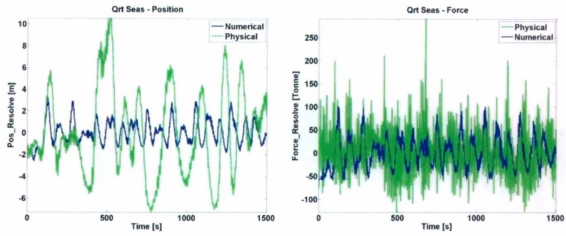

Figure 24: Numerical Quartering Seas Position and Force
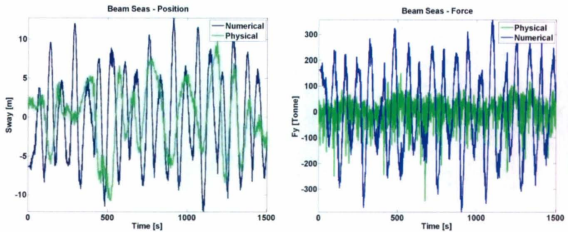

Figure 25: Numerical Beam Seas Position and Force 


\section{APPENDIX F}

\section{Uncertainty Analysis}




\section{OVERVIEW}

This section outlines the uncertainty analysis performed on the significant measurement parameters for these experiments. Uncertainty analysis is broken in to two types of uncertainty, type A and type B. Type A represents experimental error, such as model misalignment, and is evaluated by taking repeated measurements of the same experimental condition. Type B represents base level error that is inherent in each sensor, calibration, data acquisition system, and data analysis. Type A and B uncertainties are combined by their root sum of squares to form the total experimental uncertainty. Assessment of type A uncertainty can be very costly, as it requires a large number (generally greater than 10) of repeated experiements to form the uncertainty estimate for one measurement. Type B uncertainty can be calculated by summing known uncertainties of measurement devices and data acquisition components.

For the purpose of this study, funding only permitted one experiment for each data point. As such, Type A uncertainty could not be accurately assessed for the experiment as a whole, and application of appropriate standards and personnel experience in the preparation of each experiment was relied upon to create an environment which was replicated as consistently as possible. Type B uncertainty however, can be calculated for a number of parameters within the experiments; these are outlined below. Uncertainties were calculated as outlined in ITTC (2008) and JCGM (2008). 
Comparison of DP Performance Prediction Techniques for Scaled Models

\section{Mooring Force Measurement}

Mooring forces were measured for each mooring line using a single axis load cell. The signals were processed and filtered using an IOT provided 16 channel data acquisition system (DAS). The DAS component bias uncertainties were found from consultation with the IOT electronics department, utilizing factory component specifications, where possible.

For a linear calibration, such as that used for a strain gauge load cell, the characteristic regression equation is given by:

$$
y=a+b x
$$

Equation F1

Where $y$ is the physical calibration value (load), $x$ is the value outputted from the sensor (voltage) and $a$ is the $y$ axis intercept, or physical offset. For all applied loads, the bias of calibration standards was calculated by:

$$
B_{R C I}=(A C G) \sqrt{\sum_{1}^{n}\left(w_{i}\right)^{2}}
$$

Equation F2

where $A C G$ is the accuracy of calibration equipment and $w_{i}$ are physical values of calibration points. The regression intercept and slope are calculated as follows:

$$
\begin{array}{ll}
b=s_{x y} / s_{x x} & \text { Equation F3 } \\
a=\bar{y}-b \bar{x} & \text { Equation F4 } \\
\bar{x}=(1 / n) \sum_{i=1}^{n} x_{i} & \text { Equation F5 }
\end{array}
$$


Comparison of DP Performance Prediction Techniques for Scaled Models

$$
\begin{aligned}
& s_{x x}=\sum_{i=1}^{n}\left(x_{i}-\bar{x}\right)^{2} \\
& s_{x y}=\sum_{i=1}^{n}\left(x_{i}-\bar{x}\right)\left(y_{i}-\bar{y}\right)
\end{aligned}
$$

Equation F7

To ensure the data follows a linear trend the residual distances between the curve fit and measured curve fit are plotted:

$$
\text { Resid }=y_{i}-a-b x_{i}
$$

Equation F8

For a linear fit, these points should lie in a straight line. The standard deviation, or standard error of estimate of the regression analysis is found as follows, by first calculating the sum of squares of the residuals:

$$
\begin{aligned}
S S_{R} & =\sum_{i=1}^{n}\left(y_{i}-a-b x_{i}\right)^{2} \\
S E E & =\sqrt{S S_{R} /(n-2)}
\end{aligned}
$$

Equation F9

Equation F10

The acceptable uncertainty in regression analysis when identifying outliers is defined by the Prediction Limit.

$$
\text { Prediction Limit }= \pm t_{\alpha / 2, n-2} S E E \quad \text { Equation } \mathbf{F} 11
$$

Where $t_{a / 2, n-2}$ is the Student's t inverse probability density function at $a / 2$ confidence and $n-2$ degrees of freedom. Calibration values outside of the Prediction Limit are outliers and may be discarded. The remaining points are then used to calculate the curve fit uncertainty. For the purpose of these experiments, the regression intercept was not 
Comparison of DP Performance Prediction Techniques for Scaled Models

used, as all sensors were zeroed before use. The type B curve fit uncertainty present in the calibration is represented by the standard uncertainty of the slope $b$ :

$$
u_{b}=S E E / \sqrt{s_{x x}}
$$

Equation F12

All Type B (bias) uncertainties calculated above and obtained from the manufacturer specifications for the transducers and data acquisition system are summed in Table 5 to provide the total mooring load measurement bias uncertainties. It can be seen that the largest source of Type B uncertainty is provided by the data acquisition system. Total Bias Error is calculated by:

$$
u_{B}=\left(\sum_{i=1}^{n} u_{i}^{2}\right)^{0.5}
$$

Equation F13

The Type B uncertainties in the measurement of mooring forces are shown for surge and sway orientations in Table 27. The curve fitting plots for each mooring verification are shown in Figures 26-29. 
Comparison of DP Performance Prediction Techniques for Scaled Models

Table 27: Mooring Load Type B Uncertainty

\begin{tabular}{|r|c|c|c|c|}
\cline { 2 - 5 } \multicolumn{1}{c|}{} & \multicolumn{2}{c|}{ Stiffness 1 } & \multicolumn{2}{c|}{ Stiffness 2 } \\
\cline { 2 - 5 } & $\begin{array}{c}\text { Mooring } \\
\text { Force Surge }\end{array}$ & $\begin{array}{c}\text { Mooring } \\
\text { Force Sway }\end{array}$ & $\begin{array}{c}\text { Mooring } \\
\text { Force Surge }\end{array}$ & $\begin{array}{c}\text { Mooring } \\
\text { Force Sway }\end{array}$ \\
\cline { 2 - 5 } Bias & $(\mathbf{N})$ & $(\mathbf{N})$ & (N) & (N) \\
\hline Nonlinearity & 0.2 & & & $\%$ \\
\hline Hysteresis & 0.2 & 0.2 & 0.2 & 0.2 \\
\hline Standards & 0.061 & 0.061 & 0.061 & 0.2 \\
\hline Curve Fitting & 0.11 & 0.04 & 0.11 & 0.25 \\
\hline Calibration & & & & \\
\hline Gain Stability & 0.05 & 0.05 & 0.05 & 0.05 \\
\hline Zero Offset Drift & 1 & 1 & 1 & 1 \\
\hline Data Acquisition System & & & & \\
\hline Bridge Excitation Drift & 0.05 & 0.05 & 0.05 & 0.05 \\
\hline Regulation & 0.1 & 0.1 & 0.1 & 0.1 \\
\hline Total Bias Uncertainty & $1.05 \%$ & $1.05 \%$ & $1.05 \%$ & $1.08 \%$ \\
\hline
\end{tabular}



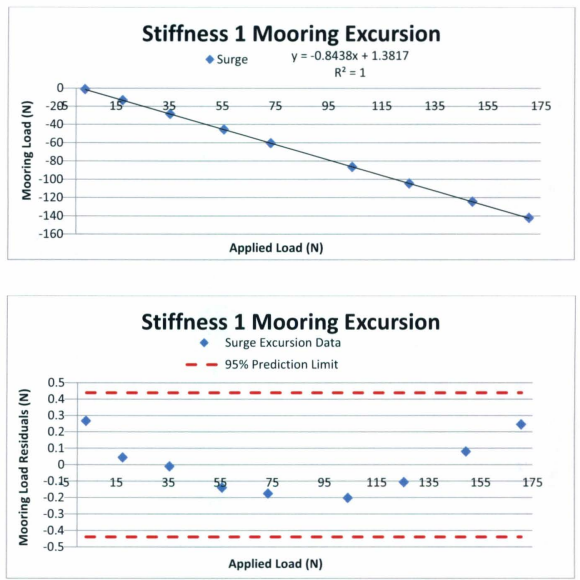

Figure 26: Stiffness 1 Mooring Surge Curve Fit 

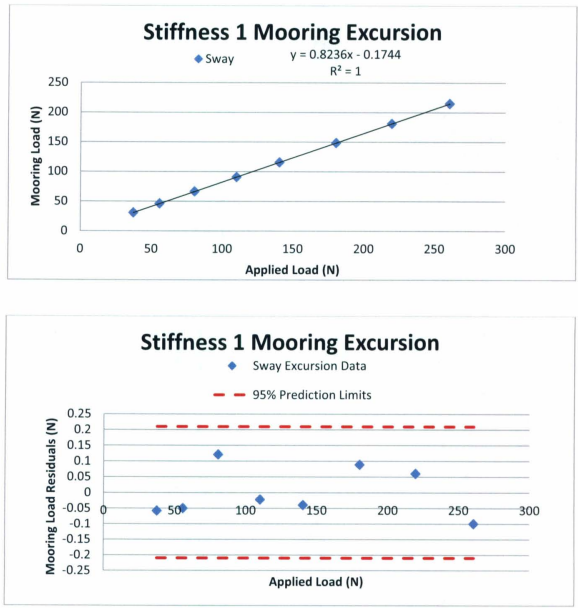

Figure 27: Stiffness 1 Mooring Sway Curve Fit 
Comparison of DP Performance Prediction Techniques for Scaled Models
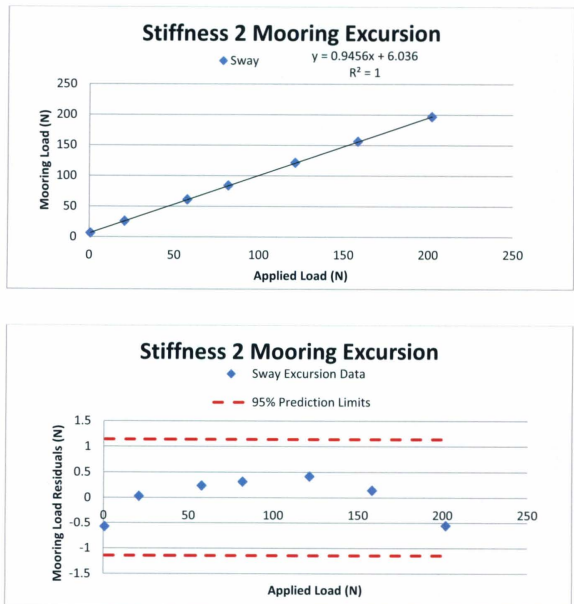

Figure 28: Stiffness 2 Mooring Sway Curve Fit 

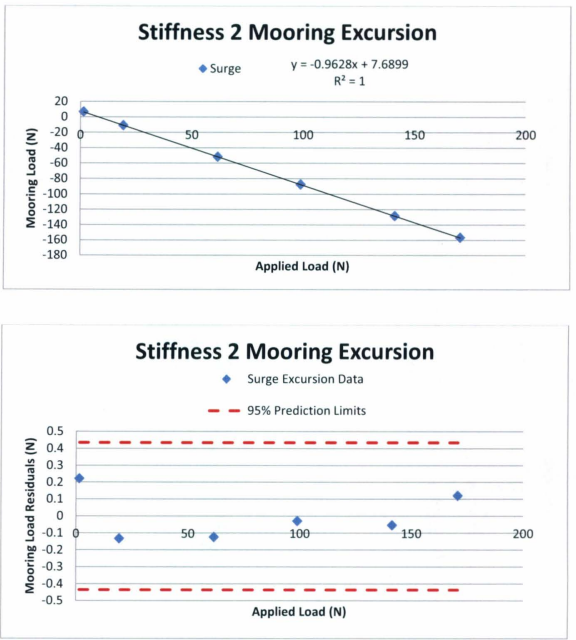

Figure 29: Stiffness 2 Mooring Surge Curve Fit 
Comparison of DP Performance Prediction Techniques for Scaled Models

\section{DP Force Measurement}

The most effective way to acquire output thrust is to instrument each thruster for unit force measurement. Unit instrumentation was not available for these experiments, so bollard lookup tables were relied upon to match commanded DP force to thruster RPM. There are many dynamic phenomena that may cause discrepancies between commanded and output thrust on a DP model; these are discussed in Sections 6.2-6.4. The magnitude of these discrepancies may be roughly equated to the variance in mean stationkeeping loads between the DP and moored experiments. For the purpose of a qualitative uncertainty analysis, without the aid of instrumented thrusters, only the bollard thrust relations in surge and sway may be analyzed. These were measured by completing DP mooring excursions, as described in Section 4.6.2.

DP Mooring Excursions are subject to the Type B mooring load measurement uncertainty, in combination with the curve fitting uncertainty in the linear regression. These components are shown in Table 28.

The DP bollard output thrust as compared to commanded (measured) thrust is found to be $93 \%$ and $92.8 \%$ in surge and sway orientations, respectively. However, no accurate correction can be applied, as during seakeeping operations, the thrust degradation due to vessel motions and thruster interaction is dynamic. The uncertainties shown in Table 28 relate to the measurements of output versus commanded thrust. The curve fitting plots are shown in Figures 30 \& 31 . 
Comparison of DP Performance Prediction Techniques for Scaled Models

Table 28: DP Force Uncertainty

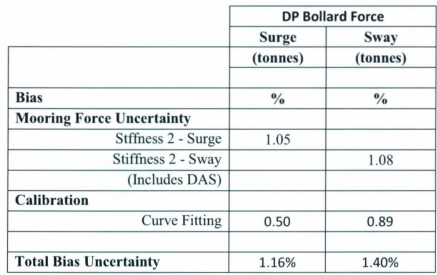


Comparison of DP Performance Prediction Techniques for Scaled Models

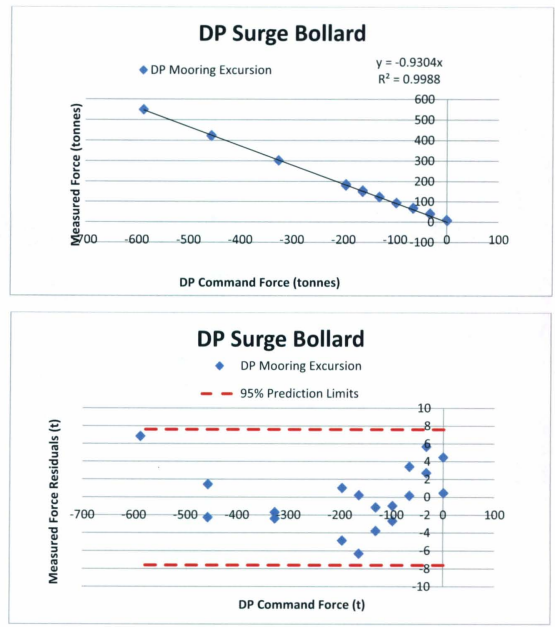

Figure 30: DP Surge Bollard Curve Fit 

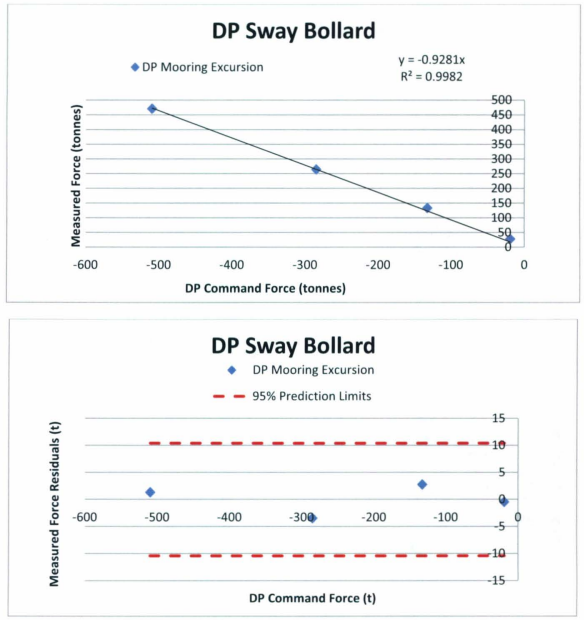

Figure 31: DP Sway Bollard Curve Fit

\section{Wave Generation}

In this study, individual experimental conditions were not repeated, however multiple conditions used the same wave train. As such, a number of independent wave analysis could be completed using the same wave probe for multiple runs. This permitted an 
analysis of both Type A and B uncertainties for significant wave height $H_{s}$ and peak period $T_{p}$. Note that both Type A and B uncertainties for wave generation, when combined, are only components of Type B uncertainty for the total experiment. In multiple test experiments, where a test is independently repeated $N$ times and $N$ data points are obtained, the Type A uncertainty associated with a sample population of $N$ readings is calculated using the following equation:

$$
u_{a}=\frac{t_{N-1} * s_{X}}{\sqrt{N}}
$$

\section{Equation F14}

Where $t_{N-1}$ is the Student's t distribution value for $(N-1)$ degrees of freedom, and $s_{x}$ is the standard deviation of the samples, defined as:

$$
s_{x}=\sqrt{\frac{1}{(N-1)} \sum_{j=1}^{N}\left(x_{j}-\bar{x}\right)^{2}}
$$

Equation F15

Where:

$$
\bar{x}=\frac{1}{N} \sum_{j=1}^{N} x_{j}
$$

Equation F16

This analysis was completed for the waves generated from the West waveboard, which were used in Phase one and two of the experiments, a total of $\mathrm{N}=5$ similar waves were analyzed. The Type A and B uncertainties are presented in Tables 29 \& 30 . 
Comparison of DP Performance Prediction Techniques for Scaled Models

Table 29: Wave Generation Type A Uncertainty

\begin{tabular}{|l|l|l|l|l|l|c|}
\hline Sample Name & Sample & $\begin{array}{l}\text { Hs } \\
(\mathbf{m}, \mathbf{M S})\end{array}$ & $\begin{array}{l}\text { Tp } \\
(\mathbf{s}, \mathbf{M S})\end{array}$ & H Residual & T Residual & t(N=4, 0.05) \\
\hline DP_HS_001 & 1 & 0.098 & 1.507 & -0.002 & -0.032 & 2.31 \\
\hline DP_HS_KO_001 & 2 & 0.099 & 1.494 & -0.001 & -0.046 & $\overline{\boldsymbol{H}_{\boldsymbol{s}}}$ \\
\hline P2_DP_HS_001 & 3 & 0.101 & 1.585 & 0.001 & 0.046 & 0.100 \\
\hline P2_DP_HS_002 & 4 & 0.099 & 1.583 & -0.001 & 0.043 & $\overline{\boldsymbol{T}_{\boldsymbol{p}}}$ \\
\hline STIFF_HS_001 & 5 & 0.097 & 1.510 & -0.003 & -0.030 & 1.540 \\
\hline P2_DP_QS_001 & 6 & 0.111 & 1.531 & 0.011 & -0.008 & $\boldsymbol{u}_{a}\left(\boldsymbol{H}_{\boldsymbol{s}}\right)$ \\
\hline P2_DP_QS_002 & 7 & 0.111 & 1.532 & 0.011 & -0.008 & $0.68 \%$ \\
\hline P2_DP_BS_004 & 8 & 0.093 & 1.553 & -0.007 & 0.013 & $\boldsymbol{u}_{a}\left(\boldsymbol{T}_{p}\right)$ \\
\hline P2_DP_BS_005 & 9 & 0.092 & 1.563 & -0.008 & 0.023 & $3.4 \%$ \\
\hline
\end{tabular}

Table 30: Wave Generation Type B Uncertainty

\begin{tabular}{|r|c|}
\cline { 2 - 2 } \multicolumn{1}{c|}{} & $\begin{array}{c}\text { Capacitance WP } \\
\text { (WP North) }\end{array}$ \\
\cline { 2 - 2 } \multicolumn{1}{c|}{ Bias } & (m) \\
\hline Transducer & $\%$ \\
\hline Dynamic (Including Meniscus) & 0.039 \\
\hline Calibration & \\
\hline Curve Fitting & 0.018 \\
\hline & \\
\hline Data Acquisition System & 0.11 \\
\hline Gain Stability & 0.05 \\
\hline Zero Offset Drift & 1 \\
\hline Bridge Excitation Drift & 0.05 \\
\hline Bridge Excitation Load \\
Regulation
\end{tabular}


Comparison of DP Performance Prediction Techniques for Scaled Models

Type A and B uncertainties are combined to form total uncertainty, as follows:

$$
U_{C}=\left(u_{A}^{2}+u_{B}^{2}\right)^{0.5}
$$

Equation F17

The total uncertainty in wave height and period are listed in Table 31. Wave probe calibration curve fitting plots are shown in Figure 32.

Table 31: Wave Generation Combined Uncertainty

\begin{tabular}{|l|l|}
\hline Wave Parameter & Combined Uncertainty $\left(\boldsymbol{U}_{\boldsymbol{C}}\right)$ \\
\hline Significant Wave Height $(\mathrm{Hs})$ & $1.2 \%$ \\
\hline Peak Period $(\mathrm{Tp})$ & $3.6 \%$ \\
\hline
\end{tabular}



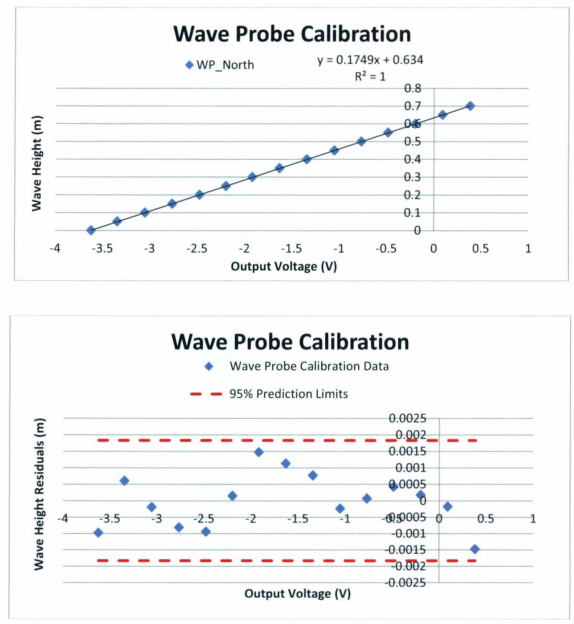

Figure 32: Wave Probe Calibration Curve Fit

\section{Wind Generation}

Wind generation uncertainty and curve fitting follows the same procedure as for Load Measurement. The same data acquisition system used in load measurement was used to acquire the wind speed and control voltage. A Gill Propeller Anemometer, Model 27106 
Comparison of DP Performance Prediction Techniques for Scaled Models

was used to measure wind speed. The Type B, Bias uncertainty is calculated in Table 32, with curve fitting plots shown in Figure 33.

Table 32: Wind Generation Type B Uncertainty

\begin{tabular}{|c|c|}
\hline & \begin{tabular}{|l|} 
Wind \\
Generation \\
\end{tabular} \\
\hline & $(\mathrm{m} / \mathrm{s})$ \\
\hline Bias & $\%$ \\
\hline \multicolumn{2}{|l|}{ Transducer } \\
\hline Propeller Speed & 1 \\
\hline Generator Voltage & 0.4 \\
\hline \multicolumn{2}{|l|}{ Calibration } \\
\hline Curve Fitting & 0.52 \\
\hline \multicolumn{2}{|l|}{ Data Acquisition System } \\
\hline Gain Stability & 0.05 \\
\hline Zero Offset Drift & 1 \\
\hline Bridge Excitation Drift & 0.05 \\
\hline $\begin{array}{r}\begin{array}{r}\text { Bridge Excitation Load } \\
\text { Regulation }\end{array} \\
\end{array}$ & 0.1 \\
\hline Total Bias Uncertainty & $1.56 \%$ \\
\hline
\end{tabular}



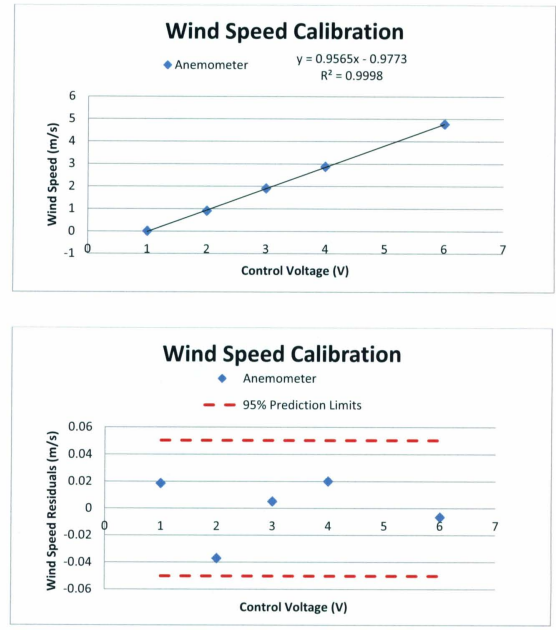

Figure 33: Wind Speed Calibration Curve Fit 



